\title{
Distribution and Projection Pattern of Motoneurons That Innervate Hindlimb Muscles in the Quail
}

\author{
SOPHIA TYRRELL, SALLY SCHROETER, LYNN COULTER, \\ AND KATHRYN W. TOSNEY \\ Department of Biology, The University of Michigan, Ann Arbor, Michigan 48109
}

\begin{abstract}
We characterized the motoneuron pool positions and projection patterns in the embryonic quail hindlimb and compared them to those in the chick to determine the degree of similarity and to form a baseline for future chimeric experiments. We find that the most similar parameters of pool position correlate with the major axonal pathway choices. First, the medial-lateral pool position, which is highly conserved among birds and mammals, is identical in the quail and chick and correlates with the dorsal-ventral pathway choice, the first and least plastic of the choices within the limb. Second, although quail pools were known to be compressed into seven rather than eight segments, we show that the map of pools is compressed about a central point (segment three) that preserves the spatial relationships between anterior pools and the crural plexus, and between posterior pools and the sciatic plexus. Access to guidance cues that are restricted to each plexus region is thus maintained between species. Third, pool position along the anterior-posterior axis is the least similar parameter between species. In fact, the entire lumbosacral motor complex may shift by \pm half a segment in individual quail. Despite the consequent differences in segmental projections, the specific projection pattern within each quail hindlimb is identical to that in the chick. There is no need to preserve the exact segmental pattern either phylogenetically or during development, because motoneurons accommodate to modest variations in their position along the anterior-posterior axis by sorting out at the limb base. The contrast between variable segmental and constant limb projections also demonstrates that neither the specification nor the precise projection of motoneurons is dependent upon the specification or development of somites.
\end{abstract}

Key words: axon guidance, motoneuron pools, neural development, phylogenetic conservation of neural characteristics, neuronal specificity, quail chick chimeras

Motoneurons that innervate the same muscle are generally organized into a cluster of cells within the spinal cord. The positions and sizes of motoneuron clusters, termed pools, have been described in a variety of animals including elasmobranchs (Droge and Leonard, '83), teleosts (Fetcho, '86a), amphibians (e.g., Silver, '42; Szekely and Czeh, '67; Cruce, '74; Stephens and Holder, '85; Fetcho, '86a; Wake et al., '88), reptiles (Fetcho, '86b), birds (Landmesser, '78a; Hollyday, ' 80 ), and mammals (e.g., Goering, '28; Romanes, '51; McHanwell and Biscoe, '81; Fritz et al., '86a,b). Motoneuron pools that innervate the extremities are located in specific positions within the lateral motor column in the ventral horn of spinal cord. In birds and mammals the relative position of pools that project to homologous limb muscles appears to be largely conserved; however, there is also considerable variation among species, particularly along the anterior-posterior axis (see reviews by Nieuwenhuys, '64; Bennett, '83). As an example, the number of segments that innervate the hindlimb can vary among birds from seven in the quail (Tanaka and Landmesser, '86a) to twelve in the ostrich (Streeter, '04). An interspecific comparison of which parameters of motoneuron organization are preserved and which parameters vary could help elucidate mechanisms for motoneuron specification and connectivity.

We have been particularly interested in the mechanisms that guide motor axons to the appropriate muscles and have used the chick hindlimb as a model system. Quail chick chimeras have proven to be a powerful technique to exam-

\section{Accepted June 8, 1990}

Address reprint requests to Kathryn W. Tosney, Natural Science Building University of Michigan, Ann Arbor, MI 48109.

S. Tyrrell is now an MSTP student at Case Western Reserve University, Cleveland, $\mathrm{OH}$.

S. Schroeter is now at Emory University, Atlanta, GA.

L. Coulter is now in the Biology Dept., University of Michigan. 
ine developmental interactions due to the ease with which transplanted cells of either species can be identified (Le Douarin, '73). However, the validity of experiments employing quail chick chimeras is dependent on the assumption that developmental processes in the two species are similar. Whereas the muscles in the hindlimb are similar in morphology and relative position during the period of motor axon outgrowth (Grim et al., '83; Tanaka and Landmesser, ' $86 \mathrm{a}, \mathrm{b})$, there are differences in the organization of the spinal cord. The most obvious is in the number of lumbosacral (LS) segments that innervate the hindlimb; there are eight in the chick (Landmesser, '78a) and only seven in the quail (Tanaka and Landmesser, '86a). In addition, the total number of chick motoneurons is approximately twice that of the quail (Tanaka and Landmesser, ' $86 \mathrm{~b}$ ). These differences imply that the motoneuron pool positions and the segmental pattern of projection of specific populations cannot be identical in quail and chick.

It has been immensely exciting to find that, despite these differences, motoneurons of one species project specifically to the appropriate muscle of the other species in chick quail chimeras (Tanaka and Landmesser, '86a), suggesting that motoneuron growth cones of quail and chick use the same navigational cues, or that each can interpret the cues of the other species. In addition, the cells and even the axons of quail can be distinguished from those of the chick by using an antibody (Lance-Jones and Lagenaur, '87). These advances validate the use of chimeric approaches in which quail neurons of known identity are confronted with surgically altered chick environments in experiments designed to tease out the location and mode of action of axonal guidance cues. For such an approach to be productive, it is essential to know in detail where the pools lie in the developing spinal cord of both species, what the axonal projection patterns are in both species, and to have a realistic assessment of the degree of variation that exists between species and among individuals of each species. However, the quail pools and their projection patterns have not been described with the detail commensurate with that of the chick. Therefore, we have mapped the major motoneuron pools and reconstructed the specific motoneuron projection pattern for the quail thigh and shank. We discuss the similarities and differences in reference to similar studies published on the chick hindlimb system (Landmesser, '78a,b; Hollyday, '80; Lance-Jones and Landmesser, '81a; Tosney and Landmesser, ' $85 \mathrm{a}, \mathrm{b}, \mathrm{c})$ and to a previous description of the segmental projection pattern of seven quail muscles (Tanaka and Landmesser, '86a).

Although our initial rationale for instigating this study was to provide a descriptive baseline for future chimeric experiments, we found that three aspects of pool position were preserved to different degrees between the chick and quail, and we identified exciting correlations between the degree to which parameters were similar and the degree of plasticity of the corresponding axonal pathway choice in the limb. These correlations have intriguing implications for the mechanisms of coordinate specification of motoneuron identities and guidance cues, for the specific guidance of axons, and for the ontological features of pool positions, which are most subject to selection pressure during evolution. Our study therefore addresses these issues as well as discussing the organization of motor pools in the quail and the practical considerations that are important to the application of quail chick chimeras to the study of motoneuron development.

\section{MATERIALS AND METHODS}

Japanese quail (Coturnix coturnix japonica) eggs from a colony maintained in our department were incubated at $38^{\circ} \mathrm{C}$ until stages $36-37$ (9-10 days of incubation) at which time muscle cleavage and innervation are complete. Embryos were staged using the criteria commonly used for chick embryos (Hamburger and Hamilton, '51), as both species develop the same characteristics in a similar sequence. Embryos were removed from the egg, decapitated, and eviscerated in oxygenated Tyrode's solution at room temperature. The skin and ventral vertebrae were removed to enhance delivery of oxygen to the spinal cord and to aid in later penetration of processing chemicals. The gross segmental and plexus nerve patterns were examined for later comparisons. We used the criteria of Romer ('27) and Schroeter and Tosney ('89) for thigh and Wortham ('48) for shank muscles in the chick to identify and name homologous quail muscles. This muscle nomenclature is consistent with publications concerning the development of motor innervation in the chick. ${ }^{1}$

Individual muscles were injected with horseradish peroxidase (HRP) and processed as described by Landmesser (78a). Briefly, the embryos were incubated in oxygenated Tyrode's solution at $34^{\circ} \mathrm{C}$ for 5 hours to allow retrograde transport of the label, fixed overnight in $2.5 \%$ glutaraldehyde in $0.1 \mathrm{M}$ cacodylate buffer at $\mathrm{pH} 7.2$, rinsed in Tris buffer for 1 week, reacted with diaminobenzidine (DAB), and embedded in paraffin. Serial, $10-\mu \mathrm{m}$ sections were stained with cresyl violet. Embryos showing any indication of incomplete injections, leakage, cut spinal nerves, or poor histological processing were discarded.

The HRP-DAB reaction product is granular and allows labeled neurons to be distinguished from other cells in the lateral motor column (Fig. 1A-D). Red blood cells and dead cells also react with DAB but are easily distinguished since red blood cells lack granules, and dead cells (which are rare by these stages) contain large clumps of reaction product rather than fine granules. Labeled motoneurons containing nucleoli were traced with a camera lucida in every third section within the lumbosacral spinal cord of the embryo and formed the basis of the reconstructions. We were primarily interested in establishing the positions of pools; however, we also counted the labeled neurons in a subset of embryos in which labeling was especially distinct in all relevant sections and we could be certain that we were detecting all labeled cells. These cell counts were multiplied by three. Because we included only cells with nucleoli, no correction factor was used; this method correlates well with data obtained by counting every section and multiplying by a correction factor (Lance-Jones, '86).

Segmental boundaries were defined as the midpoint between dorsal root ganglia using the criterion of Landmesser ('78a); our use of the same criterion assures that our manner of designating the segmental position of pools in the quail is the same as that previously used in the chick. As pointed out by Tosney ('88a), this designation does not

'The generally accepted modern names for muscles (Vanden Berge, '79) are in parentheses as follows: accessory (accessorius), adductors (puboischiofemoralis lateralis and medialis), ambiens (same), caudilioflexorius (flexor cruris lateralis), femorotibialis (femorotibialis externus, medius, and internus), gastrocnemius pars interna and media (gastrocnemius pars medialis and intermedia), iliofibularis (same), iliotibialis (iliotibialis lateralis), iliotrochantericus I and II (iliotrochantericus caudalis and cranialis), ischioflexorius (flexor cruris medialis), obturator externus and internus (obturatorius lateralis and medialis), peroneus longus (fibularis longus), sartorius (iliotibialis cranialis), tibialis anterior (tibialis cranialis). 
correspond directly to earlier somitic segments. Segmental levels were determined by the nerve pattern and the position of the last rib. The A-P dimensions of the spinal cord varied among quail embryos, as it does in the chick,
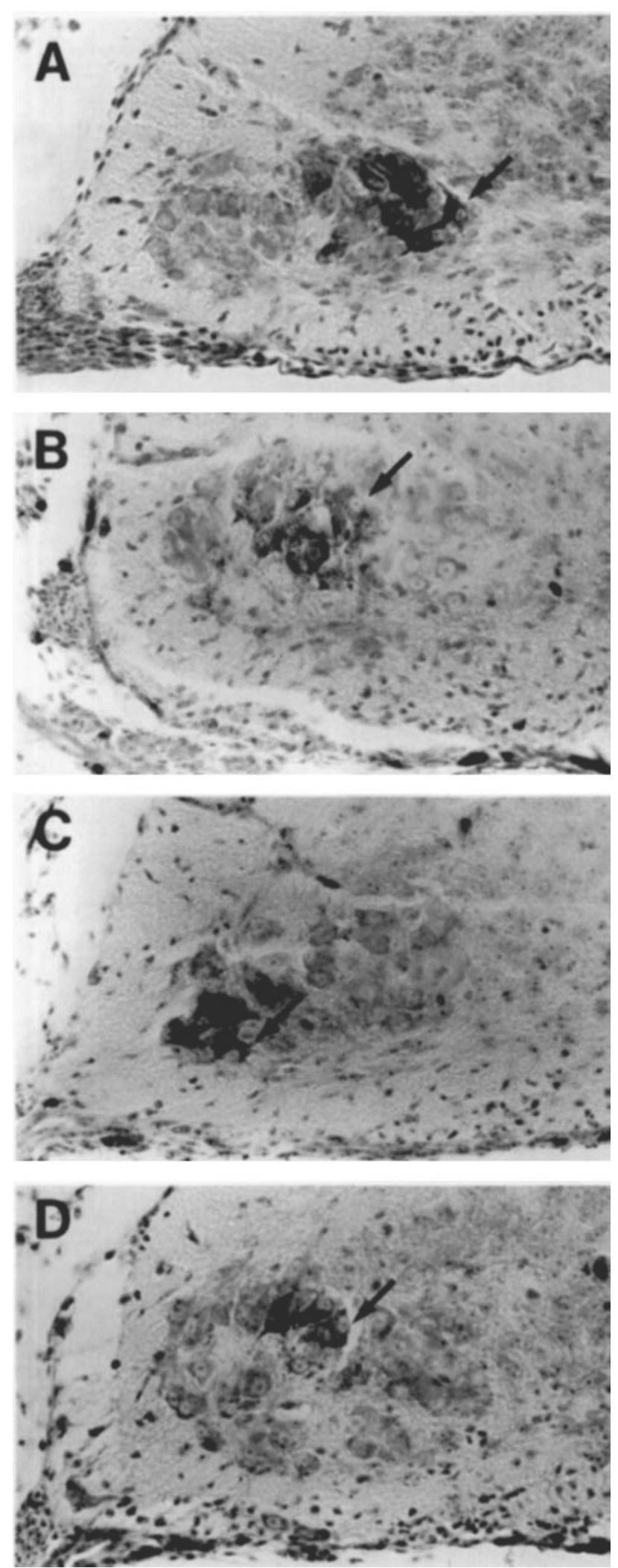

and it was necessary to normalize the data. Each segment within the lumbosacral region was divided into ten equal portions. The percentage of the entire pool within each portion was calculated and plotted against its relative segmental position (Figs. 2-5), following the conventions of Landmesser ('78a). This method emphasizes the spatial distribution of motoneurons contributing to each pool rather than their absolute number and allows histograms from individual animals to be combined and compared. The distribution of neurons within two quail pools, the sartorius and adductors, have also been previously described in this manner (Tanaka and Landmesser, '86a). We emphasize that we have used the reliable and easily applied criteria for segments, for pool positions, and for graphical representation of data that have been used by Landmesser and her colleagues; those species-specific differences in pool position that we describe are therefore unlikely to be due to differences in criteria.

The relative positions of pools along anterior-posterior (AP), dorsal-ventral (DV), and medial-lateral (ML) axes were reconstructed by superimposing, in $\mathrm{AP}$ order, five camera lucida tracings from each segment; the reconstruction of each pool combines tracings from several embryos and reflects an average position (Figs. 6, 7). The tracings were projected onto a screen to fit a standard cross section and aligned using the medial boundary of the lateral motor column. The region containing labeled neurons was traced after discarding the most scattered $5 \%$ of the total number of labeled cell bodies in each embryo. The position of quail pools was compared to those for the chick described by Landmesser ('78a,b) and by Hollyday ('80). Most of our comparisons are to Landmesser ('78a) since she determined numbers as well as positions of motoneurons and used more complete muscle injections. We emphasized the characterization of pools associated with those muscles that would be most accessible for experimental manipulation and assay, including the larger muscles of the thigh and the dorsal and ventral muscle groups in the shank, but we also mapped a subset of the smaller thigh and larger shank muscles in a few embryos.

To characterize motor projection patterns, quail eggs were incubated until stage 27-33 (when the projection patterns are similar to those found in the adult) and prepared as described above except that individual spinal nerves or nerve trunks, rather than muscles, were injected with HRP. The label was transported in an orthoretrograde fashion and labeled axons darkly, which were then easily distinguished and traced from their somata to their termination within muscle. The projection patterns were reconstructed from camera lucida tracings of serial, $12-\mu \mathrm{m}$ sections (Fig. 8).

Fig. 1. Light micrographs illustrating the position of pools in the transverse plane in the second LS segment. The pool for the internal and external adductor muscles (A) lies at the most medial edge of the motor column in accord with the derivation of the adductor muscles from the ventral muscle mass. The other pools mapped in this segment project to muscles derived from the dorsal muscle mass. The anterior iliotibialis pool (B) lies dorsolaterally, the sartorius pool (C) lies ventrolaterally; the femorotibialis pool $(\mathbf{D})$ lies centrally and begins in the posterior portion of the segment. The AP disposition of pools is shown in Figure 6. Pools that lie centrally may project to either dorsal or ventral muscles; however one rule always obtains: All pools projecting to ventral muscles lie medial to all pools projecting to dorsal muscles. Arrow indicates a labeled neuron in each figure. Bar $=10 \mu \mathrm{m}$. 
A. anterior iliotibialis

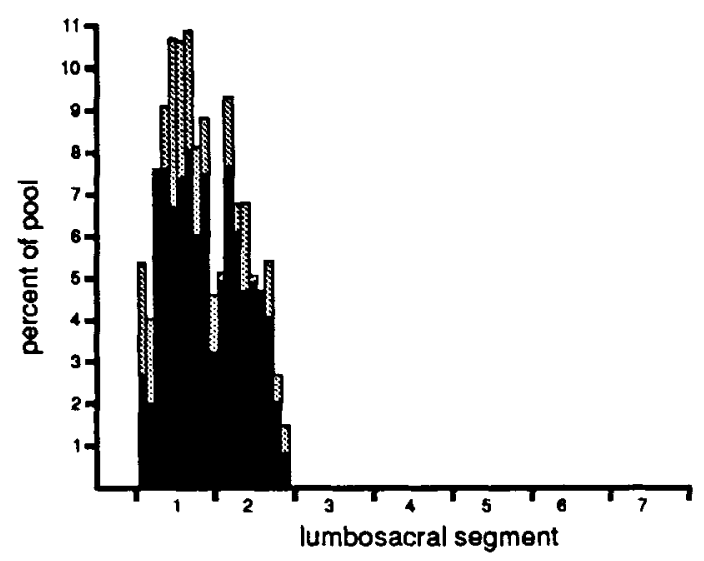

C. ambiens

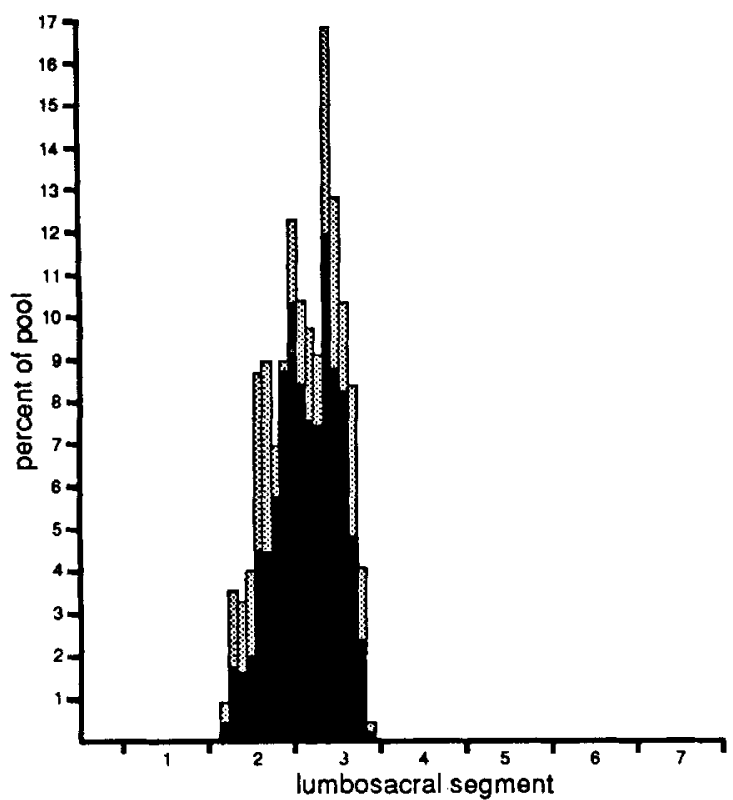

E. sartorius

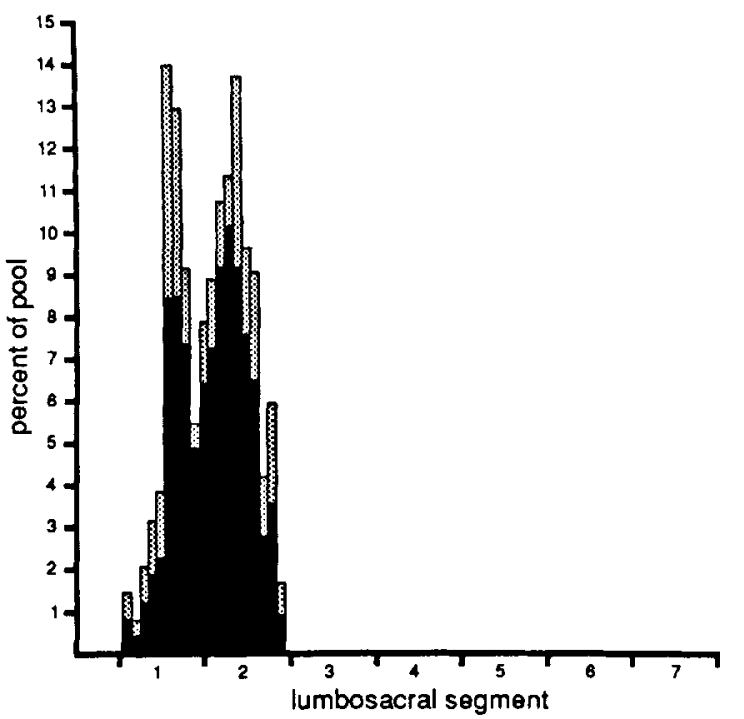

B. posterior iliotibialis

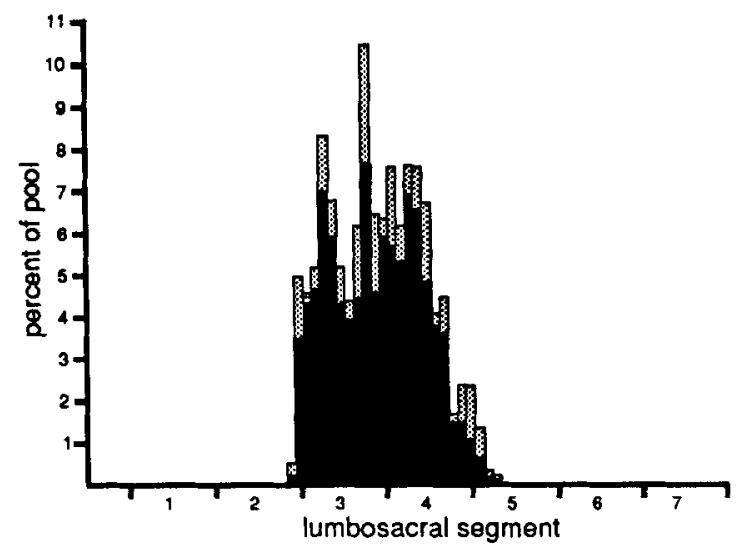

D. femorotibialis

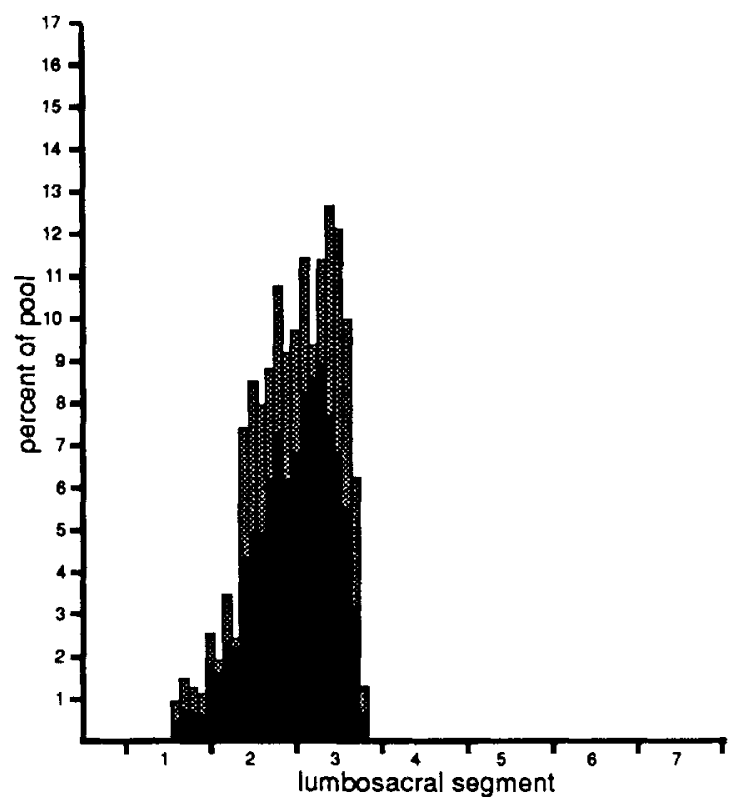

F. iliofibularis

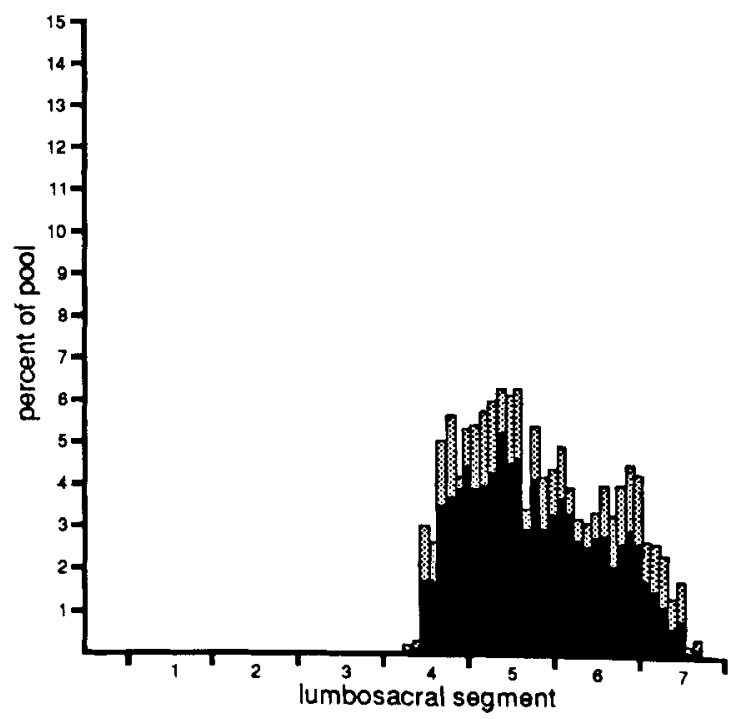

Figure 2 


\section{RESULTS}

We first briefly describe our identification of quail pools before comparing our results to those previously found in the chick. Unless other references are given, authority for statements on the pool disposition in chicks can be found in Landmesser ('78a,b) and, for the subset of shank muscles we mapped, in Hollyday ('80).

\section{Quail motoneuron pools}

Motoneuron pools were identified as coherent clusters of labeled cells. Pools within each segment are spatially organized along the ML and DV axes of the lateral motor column. We illustrate this organization using transverse sections through the second LS segment (Fig. 1A-D). In this segment only the adductors pool projects to muscles derived from the ventral muscle mass and this pool lies at the most medial edge of the motor column (Fig. 1A). Pools that innervate muscles derived from the dorsal muscle mass lie laterally and in characteristic relative positions. Two pools mark the lateral edge of the lateral motor column; the anterior iliotibialis pool (Fig. 1B) lies dorsally, the sartorius pool (Fig. 1C) lies ventrally. The femorotibialis pool lies between these and the adductors pool (Fig. 1D), Camera lucida tracings of similar sections were used to plot the AP distribution of labeled cells in each pool (Figs. 2-5) and to reconstruct the relative position of pools along all three embryonic axes (Figs. 6, 7). These presentations use the same parameters that Landmesser ('78a) used in describing chick pools and can be directly compared with hers. The relative position of quail pools is also similar to that for chick described in Hollyday ('80). The few divergences between these two may be attributable to the less complete muscle injections used by Hollyday.

As in the chick, the boundaries of individual pools are not smooth and vary slightly from section to section within an animal. While a few labeled cells lie outside each cluster, it is to be emphasized that there is no extensive overlap or intermingling of different pools. The reconstructions (Figs. $6,7)$ overemphasize the amount of overlap because they combine sections from different embryos that vary in stage and in size. The highest degree of overlap was usually evident in the trailing anterior and posterior ends of each pool.

Fig. 2. The AP distribution of motoneurons within lateral motoneuron pools projecting to thigh muscles derived from the dorsal muscle mass. Histograms show the mean \% of each pool within successive increments along the LS cord. The lighter shading (drawn in only one direction) represents the standard error of the mean (S.E.). The mean number of neurons for each pool plus or minus S.E. is given in parentheses below. A. Anterior iliotibialis pool $(207 \pm 12$ cells, $n=2)$ The position of this pool was confirmed from camera lucida tracings of labeled neurons in 2 additional embryos. B. Posterior iliotibialis pool ( $430 \pm 2$ cells, $n=2$ ), position confirmed in I additional embryo. In the chick, the anterior and posterior iliotibialis pools were mapped as a unit; the number in the combined quail pool is $48 \%$ of the number of the combined chick pool. C. Ambiens pool ( $223 \pm 28$ cells, $n=2)$, position confirmed in 1 additional embryo. D. Femorotibialis pool ( $334 \pm 2$ cells, $\mathrm{n}=2$ ), position confirmed in 2 additional embryos. The pools for the ambiens and femorotibialis were mapped as a unit in chick; the number of neurons in the combined quail pool is $49 \%$ of the number in the combined chick pool. E. Sartorius pool $(235 \pm 37$ cells, $\mathrm{n}=3 ; 59 \%$ of the number in the chick pool), position confirmed in 5 additional embryos. F. Iliofibularis pool ( $366 \pm 64$ cells, $n=4 ; 62 \%$ of the number in the chick pool).
Studies early in this century emphasized the anatomical clustering of neurons into several columns within medial and lateral motor columns in various species. However, as in the chick, individual motor pools are not necessarily colinear with or wholly contained within a particular anatomical column. Any functional or ontogenetic correlate of an anatomical clustering of somata has yet to be documented, as discussed in more detail by Hollyday ('80) and Fritz et al. ('86b).

\section{Similarities between motoneuron pools in quail and chick}

The most consistent similarities are in the relative position of pools along the ML axis (Figs. 6, 7). In both species, pools that project into dorsal nerve trunks in the limb and innervate muscles derived from the embryonic dorsal muscle mass (sartorius, femorotibialis, iliotibialis, ambiens, iliofibularis, deep dorsals, and dorsal shank muscles), lie lateral to pools that project into ventral nerve trunks and innervate muscles that are derived from the embryonic ventral muscle mass (adductors, ischioflexorius, accessory, caudilioflexorius, and ventral shank muscles). The histograms illustrating the AP distribution of neurons for each pool have been grouped to emphasize this somatotopy and show medial (Fig. 2A-F) and lateral (Fig. 3A-D) pools for thigh muscles and medial (Fig. 4A-C) and lateral (Fig. 5A-D) pools for shank muscles.

The relative positions of pools are preserved along the DV axis to a lesser but still considerable extent. For example, the four pools illustrated in Figure 1A-D lie in the same relative position to one another in quail and chick. The few differences we find in DV position are confined to a portion of a pool. The most anterior portions of the peroneus longus and gastrocnemius pars interna are more ventral than in the chick; the most anterior portion of the caudilioflexorius lies more dorsal than in the chick. The DV organization of pools has been suggested to be related to the proximal-distal muscle position in mammals (Romanes, ' 51 , '64), but this relationship is not generally apparent for the chick or for the quail. As in the chick, thigh muscles with proximal origins are innervated by pools that are located dorsally (such as the ischioflexorius and iliofibularis) as well as by pools that are located ventrally (e.g., sartorius). In addition, our ability to detect differences in pool position along DV axis in cross sections suggests that we could have detected differences in pool position along the ML axis in the same cross sections had significant differences been present. The relative constancy of pool position along the ML axis is unlikely to be due to sampling error.

The majority of pools are also located in the same relative order along the AP axis, an order that roughly reflects the embryonic (rather than the adult) AP position of muscles within the limb of both species, e.g., the sartorius, adductors, ischioflexorius, and caudilioflexorius pools for thigh muscles (Fig. 6). The somatotopy is not exact in either species, e.g., pools for all the shank muscles lie anterior to the caudilioflexorius pool of the thigh. All pools, with the exception of the accessory, the iliotibialis, and the peroneus longus pools described below begin and end in the same AP order in both species.

The similarity in distribution of pools extends to the shape of most of the individual pools. For instance, in both animals the iliofibularis pool is long and thin and is 
A. adductor

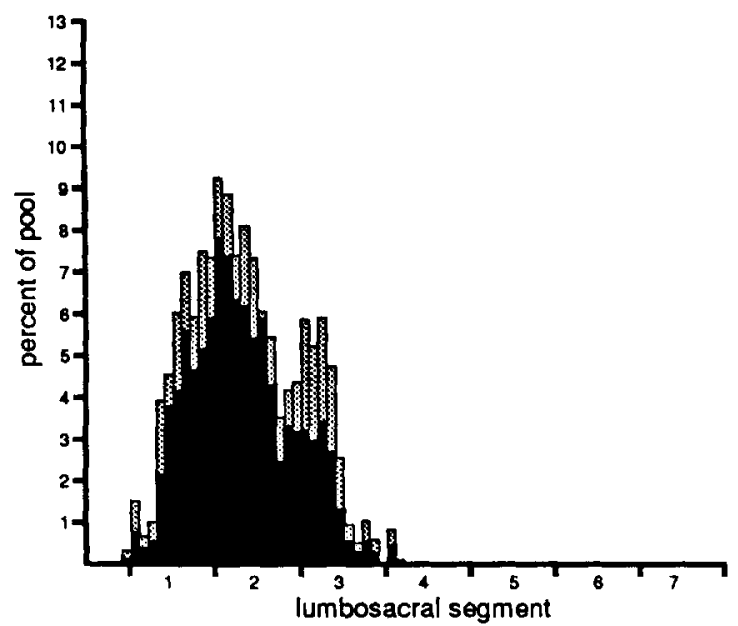

C. ischioflexorius

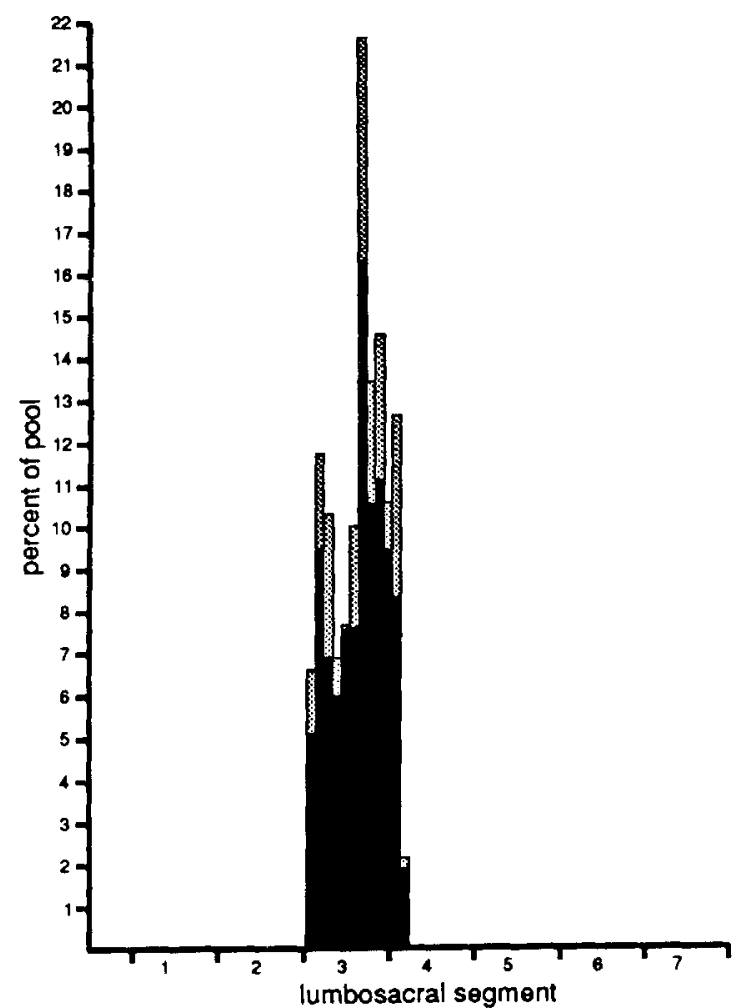

Fig. 3. The AP distribution of motoneurons within medial motoneuron pools projecting to thigh muscles derived from the ventral muscle mass. Data presented as in Figure 2. A. The pools for the two adductor muscles were mapped as a unit, as they also were in chick (504 \pm 54 cells, $n=3 ; 84 \%$ of the chick number). The position of this pool, which is more extensive along the AP axis than in chick, was confirmed in 6 additional embryos. B. Accessory pool ( 75 cells, $n=1 ; 65 \%$ of the chick

characterized by a relatively constant number of cells at each point along the AP axis (Figs. $2 \mathrm{~F}, 6$ ); the sartorius pool is short and a large proportion of the cells is concentrated in a central portion of the pool (Figs. 2E, 6). Even the adductors pool, which has a larger proportion of the total number of LS motoneurons in the quail than in the chick,

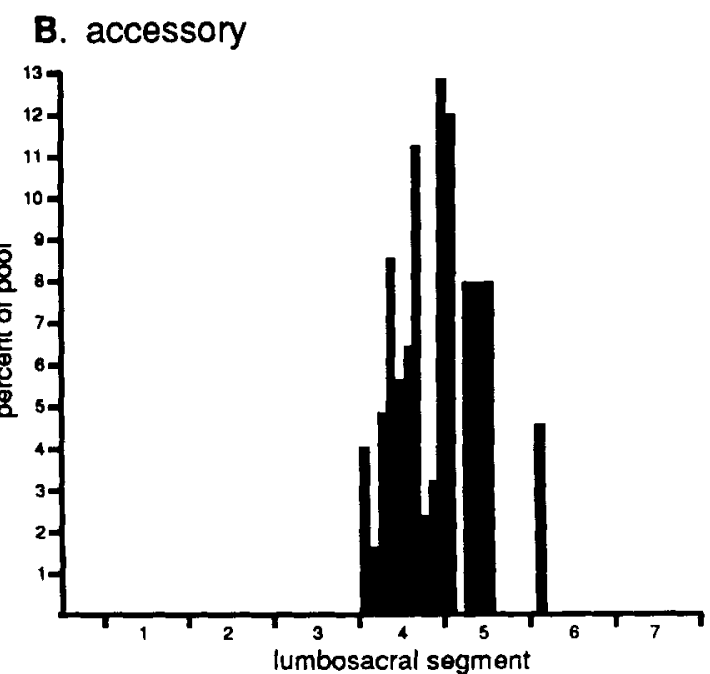

D. caudilioflexorius

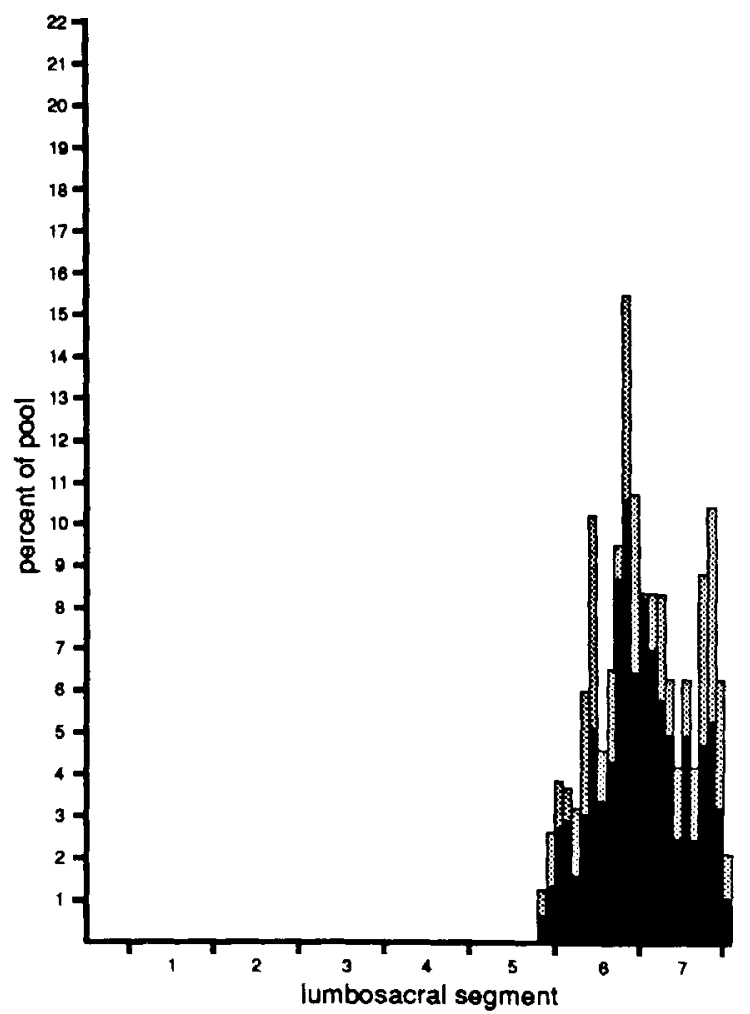

number). This pool lies much more rostrally in quail than in chick, both with respect to segmental levels and to neighboring pools. Its position was confirmed in 3 additional embryos. C. Ischioflexorius pool (103 \pm 2 cells, $\mathrm{n}=2 ; 44 \%$ of the chick number), position confirmed in 2 additional embryos. D. Caudilioflexorius pool ( $157 \pm 13$ cells, $n=2$; $51 \%$ of the chick number), position confirmed in 4 additional embryos.

has the same shape in both (Figs. 3A, 6). Similarly, as previously pointed out by Landmesser ('78a), the complex shape of the chick ischioflexorius pool is similar in every detail to that of the homologous semimembranosus pool in the cat (Romanes, ' 51 ) and is identical to the shape that we have documented in quail (Figs. 3C, 6). 


\section{Differences between motoneuron pools in quail and chick}

The most obvious differences between the quail and chick lie in the segmental positions of pools. Only seven (rather

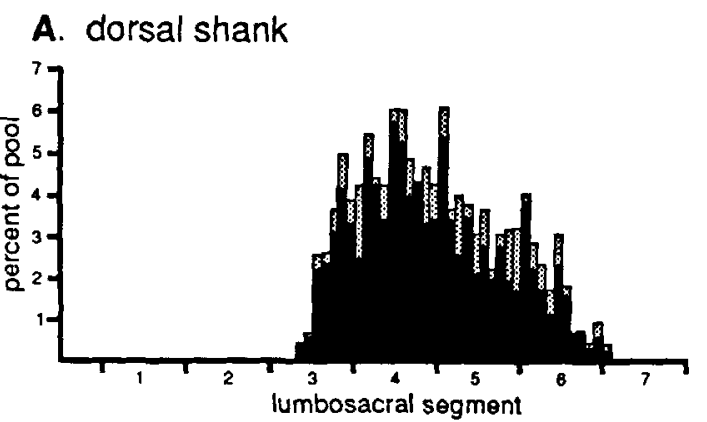

\section{B. peroneus longus}

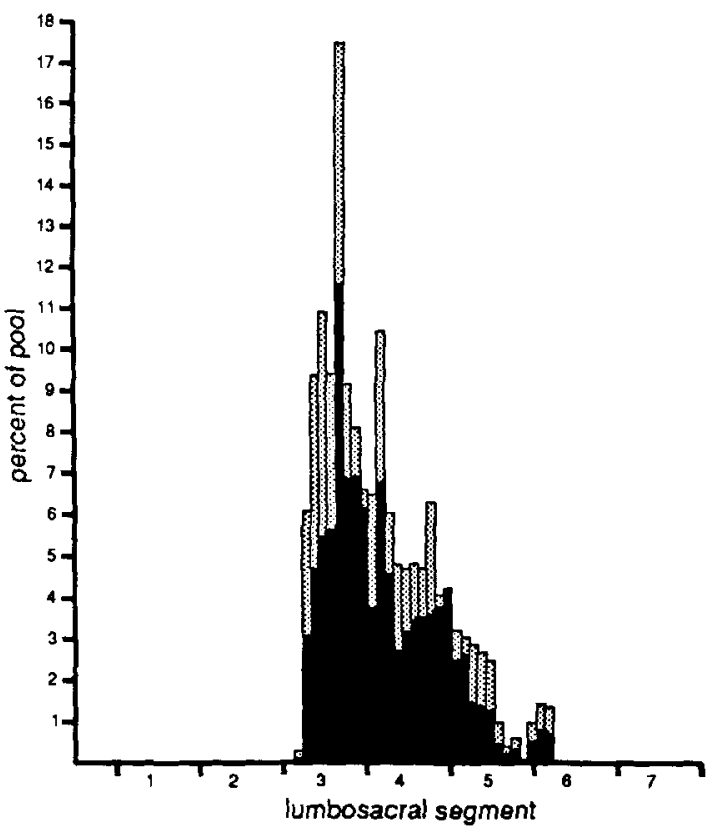

\section{C. tibialis anterior}

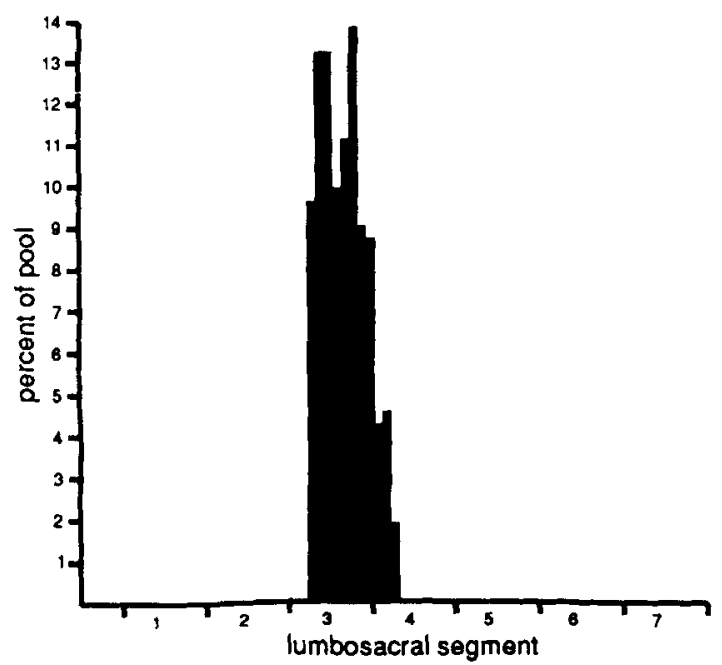

than eight) segments contribute to hindlimb innervation in quail and the AP extent of the motoneuron map is consequently compressed; the majority of the quail pools are shifted toward the central LS segments relative to those in the chick (Fig. 6). This compression results in real segmental differences in motoneuron pool position. The more posterior pools, including those for the ischioflexorius, accessory, caudilioflexorius, flexor digitorum longus, gastrocnemius pars interna, peroneus longus, and tibialis anterior, are in more anterior segmental positions in quail. This shift in pool position varied from approximately one-fourth to a full segment. In the majority of these pools, the shift was less pronounced at the anterior and most extensive at the posterior edge of the pool. For instance, the posterior tip of the caudilioflexorius pool ends one segment more rostrally in the quail than in the chick; its anterior tip is shifted rostrally by only half a segment.

Whereas Tanaka and Landmesser ('78a) stressed the rostral shift of posterior pools in quail, which is most evident in segmental projection patterns that they assessed, we find that anterior pools likewise tended to be shifted and were found more caudally than in chick. For instance, in the quail the sartorius pool does not extend into the last thoracic segment and the peak in motoneuron number is in LS2 rather than LS1; the ambiens begins nearly a full segment caudally relative to chick. These shifts have less consequence for the segmental projection pattern since only the relative contribution to each of the three anterior segments differs for three of the major pools (the anterior iliotibialis, the femorotibialis, and the sartorius) and only the adductors pool extends into a segment (LS3) that it seldom occupies in any numbers in chick. We also document the presence of the trailing ends of several pools in segments that Tanaka and Landmesser ('86a) did not; these workers would not be expected to have detected these using electrophysiology or their relatively small HRP injections. The only discrepancy between our results is in the extent of the posterior iliotibialis pool, which we find somewhat more rostral than they reported.

The most surprising and novel observation we made is that the directions of shift are those one would expect if the map compressed or expanded about a central point. This central point is in segment LS3, the only segment containing pools that project to both crural and sciatic plexuses. In no case, for instance, are anterior pools that innervate crural targets shifted so far caudally that they come to lie in segment LS4. Likewise, posterior pools that extend well into LS3 in the chick are never shifted into LS2 in the quail; the rostral shift in these pools is often confined to a shift in the posterior end point, with the anterior endpoint relatively unchanged. The compression of the motoneuron map about the third segment has a very important consequence for patterns of projection; it assures that the relative position of anterior pools and the crural plexus and the

Fig. 4. The AP distribution of motoneuronss within lateral pools projecting to shank muscles derived from the dorsal muscle mass. Data presented as in Figure 2. A. All dorsal shank muscles (609 \pm 117 cells, $n=2 ; 48 \%$ of chick number). The position of this conglomerate pool was confirmed in 6 additional embryos. The larger variation in number within this pool can be ascribed to the difficulty in fully injecting each of the small deep muscles of the shank. The numbers of motoneurons in pools for individual shank muscles have not been determined in chick embryos. B. Peroneus longus $(279 \pm 42$ cells, $n=2)$, position confirmed in 3 additional embryos. C. Tibialis anterior ( 99 cells, $n=1$ ), position confirmed in 2 additional embryos. 
A. ventral shank

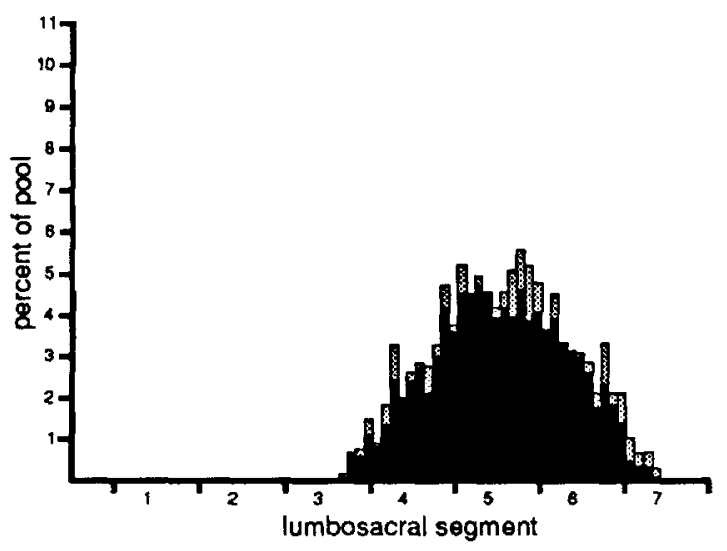

C. gastrocnemius pars media

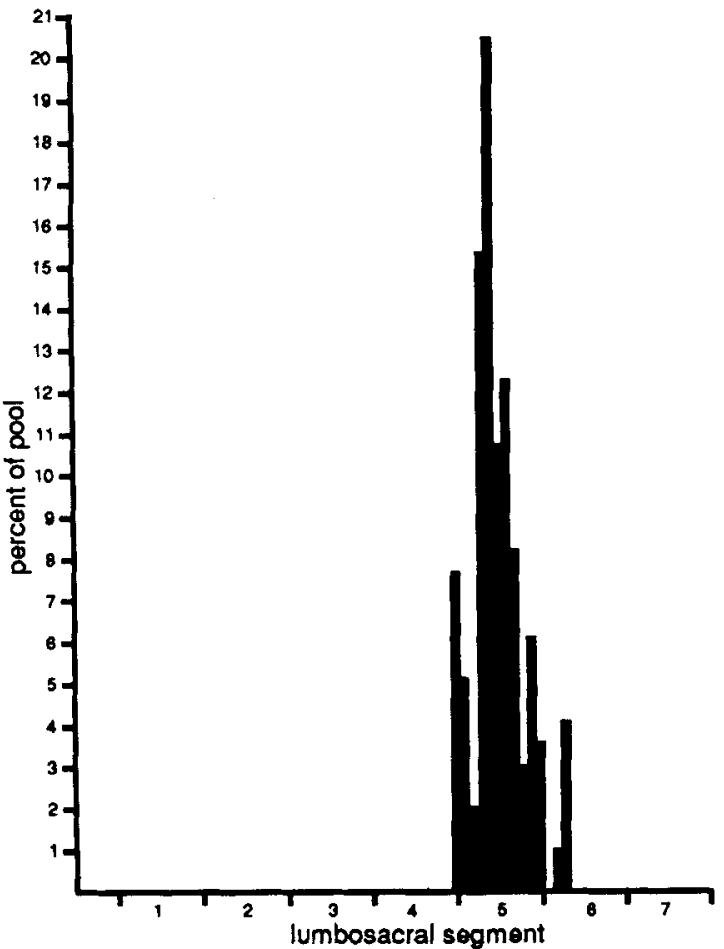

Fig. 5. The AP distribution of motoneurans within medial pools projecting to shank muscles derived from the ventral muscle mass. Data presented as in Figure 2. A. All ventral shank muscles (1778 \pm 64 cells, $\mathrm{n}=2 ; 49 \%$ of chick number). The position of this conglomerate pool was confirmed in 2 additional embryos. B. Flexor digitorum longus

relative position of posterior pools and the sciatic plexus is the same in both species. The preservation of this parameter of motoneuron pool position may reflect the differential accessibility of axonal guidance cues in crural vs sciatic plexus regions, and suggests that pool position along the $\mathrm{AP}$ axis is ontologically and perhaps phylogenetically preserved

\section{B. flexor digitorum longus}

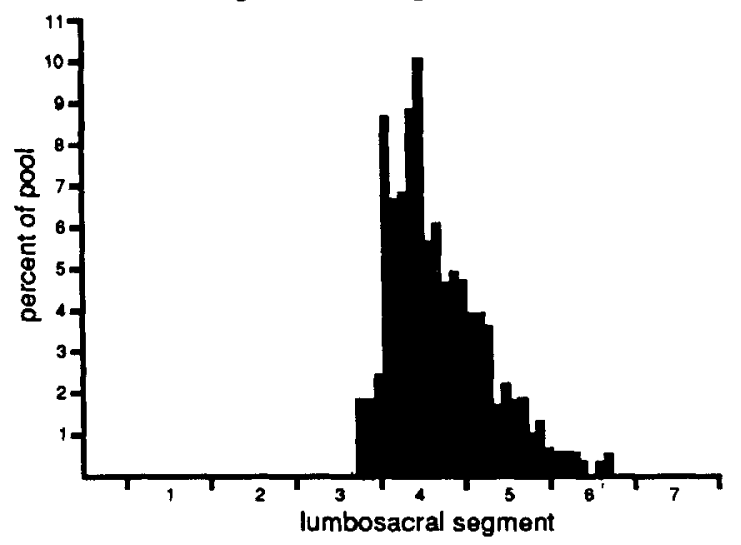

D. gastrocnemius pars interna

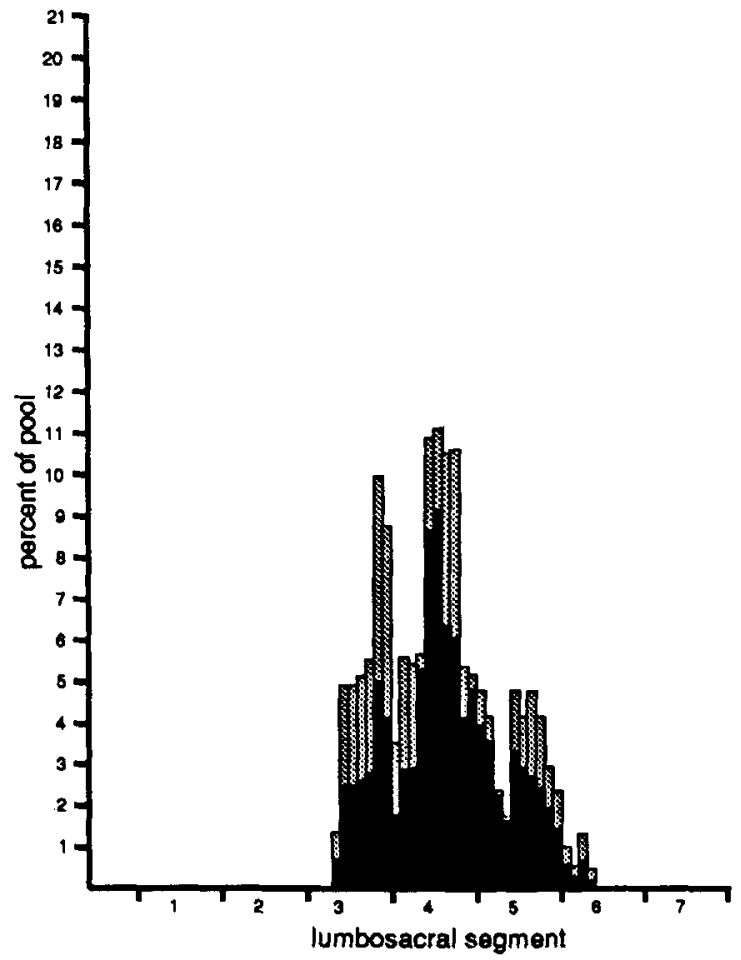

pool ( 393 cells, $n=1$ ), position confirmed in 1 additional embryo. $\mathbf{C}$. Gastrocnemius pars media pool (117 cells, $n=1$ ), position confirmed in 1 additional embryo. D. Gastrocnemius pars interna (457 \pm 34 cells, $\mathrm{n}=2$ ).

in regard to the constraints on axonal pathway selection that are present at the base of the limb.

The compression of pool position along the AP axis was usually accompanied by a similar compression within each pool along this axis. The most striking example is the ischiofiexorius. This pool occupies LS3 and LS4 in the chick 


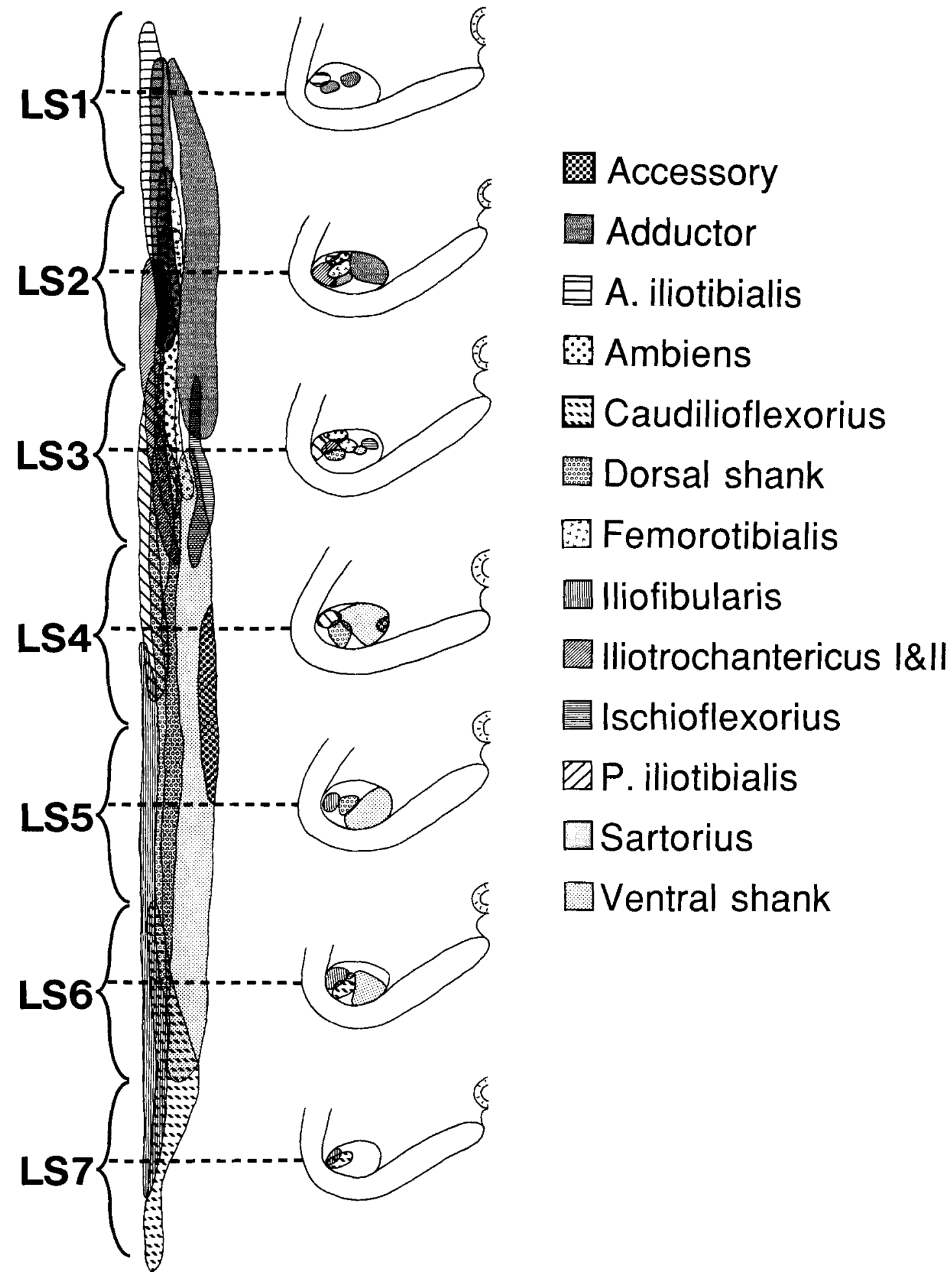

Fig. 6. Reconstruction of the positions of motoneuron pools that innervate quail thigh muscles and the dorsal and ventral complexes of shank muscles. The extent and relative position of motor pools is shown along the horizontal plane and, at right, along the transverse plane of each segment. The most scattered $5 \%$ of labeled neurons has been discarded; since these were often at the anterior and posterior ends of the pool, a pool may appear shorter in this reconstruction than in the corresponding histogram. The lateral motor column is represented as a cylinder; segment-specific differences in its transverse dimensions were obscured when the data from different embryos was normalized as described in the methods. Likewise, each segment is represented by the same length, to normalize for the considerable variation in AP length of each segment that we found in quail. The average length of a segment was $103 \pm 49 \mu \mathrm{m}$ in stage 37 embryos. The greatest difference was seen in LS3, which ranged from 260 to $425 \mu \mathrm{m}$ in stage 36 embryos and from 385 to $490 \mu \mathrm{m}$ in stage 37 embryos. The variation in AP segmental length adds to the heterogeneity we find along the AP axis. The density of labeled cells within pools can be obtained by consulting the corresponding histograms for each pool (Figs. 2-5). 


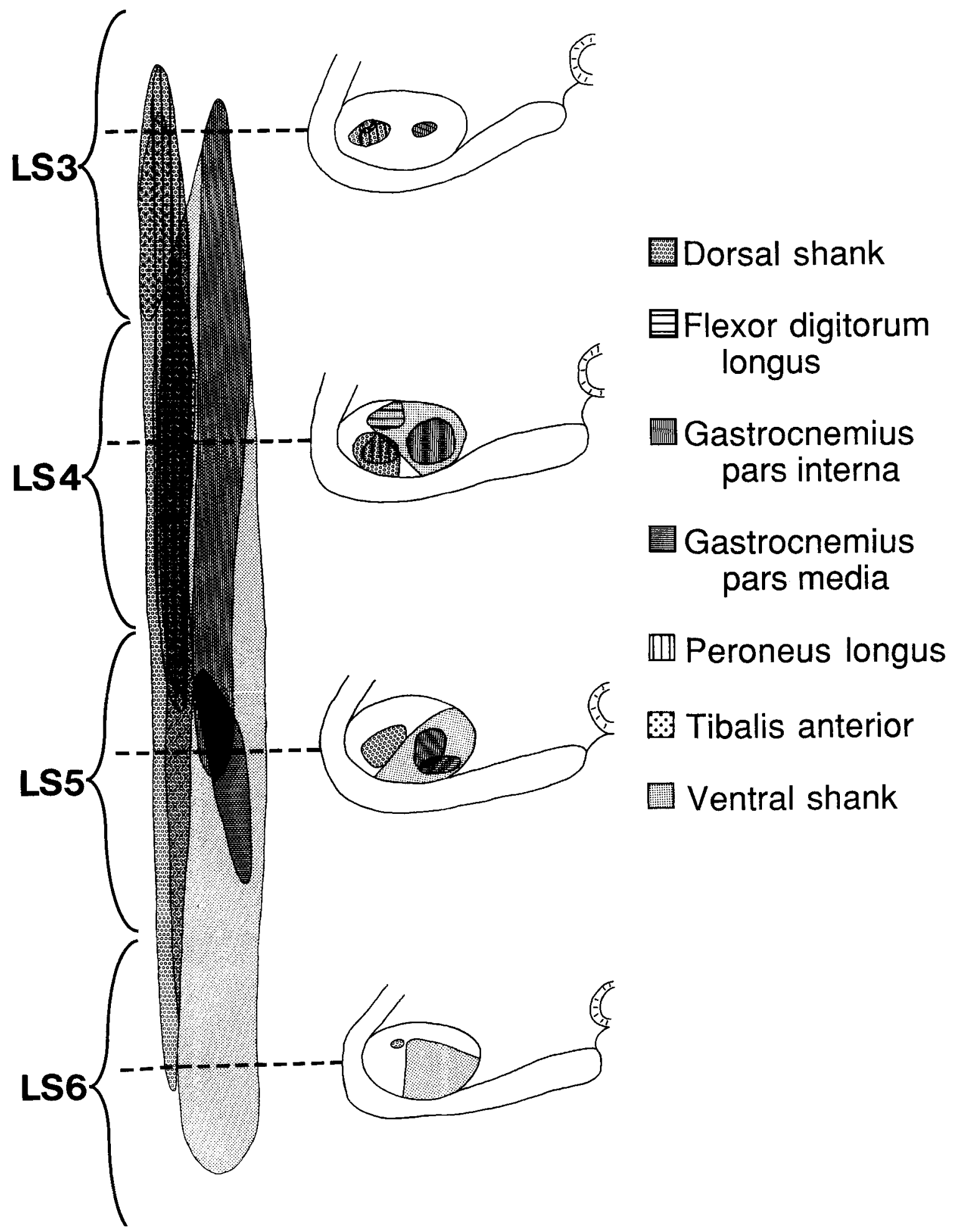

Fir. 7. Reconstruction of the positions of motoneuron pools that innervate a major subset of muscles in the quail shank. The extent and relative position of motor pools is shown along the horizontal plane and, at right, along the transverse plane as described in Figure 6. 
and is almost wholly contained within LS3 in the quail. The majority of pools were a quarter to a full segment shorter along the AP axis, conforming with the notion of a compressed but otherwise conserved motoneuron map. In addition, even those few pools that change little in segmental extent and position demonstrate a shift in cell density toward the central segments, e.g., the highest proportion of cells in the iliofibularis is in segments LS4 and LS5 in the quail and LS5 and LS6 in the chick.

There are, however, differences that cannot be related to compression of the lateral motor column along the AP axis. First, the bulk of the anterior iliotibialis pool was shifted rostrally by nearly a full segment; in the chick, only a few neurons are found in an anterior trailing edge of the pool within LS1, whereas in the quail a significant proportion of the pool is found in this segment (Fig. 2A). The direction of the shift is contrary to that expected from a general compression and, in addition, brings this pool into a different spatial relation to its neighbors in LS1 (Fig. 6). Second, we found that the anterior and posterior iliotibialis pools (Fig. 2A,B) are more separated along the A-P axis than in the chick where these pools were mapped as a single unit. This may indicate that these pools are more separate in quail with the highest density of cells within each pool shifted in opposite directions relative to the regions in which these pools overlap in the chick. Alternatively, the distribution may reflect the difficulty in fully injecting these very thin muscles in the region where they attach to a common tendinous sheet. Third, the peroneus longus pool is shifted rostrally by more than a segment. Whereas the direction of shift conforms with the notion of general compression, the extent of the shift alters the relative order of pools and brings this pool into a different spatial arrangement with its neighbors. Fourth, a general compression of the map predicts that all pools would extend a shorter distance along the AP axis, and this is seen in the majority of pools. However, the adductors pool is actually longer in the quail, beginning in a more anterior position and ending in a more posterior position than in the chick.

Our findings that all quail pools are not consistently shifted toward the central regions of the LS motor column, that the relative position of pools along the AP axis is not strictly maintained, and that all pools are not condensed in size along the $\mathrm{AP}$ axis to a similar extent demonstrate that the quail lateral motor column is not a simple replica of the chick column that has been compressed into seven rather than eight segments. Modest quail-specific differences in motor pool placement do exist along the AP axis.

\section{Comparison of the number of motoneurons per pool in quail and chick}

Although it was not a major focus of our study, we also determined the number of motoneurons in selected quail pools. In the great majority of quail pools, the number is roughly one-half of those of the chick, in agreement with Tanaka and Landmesser's ('86b) report that the total number of quail LS motoneurons is half that of the chick. These researchers also showed that the numbers of neurons in a quail pool they selected for more detailed analysis (the sartorius) is half that of the chick, in agreement with our assessment. Despite the reduced number of neurons in each pool, the relative size of each quail pool is generally comparable to those of the chick (Figs. 2-5).

The pool for the adductors is an exception to the proportional decrease in pool size in quail. The mean number of neurons in the quail pool is $84 \%$ of the number in the chick pool (consistent with the histogram for this pool in Tanaka and Landmesser, '86a). We thus confirm that the pool for the adductors is truly divergent from the general pattern seen in the chick and quail, both in the relative number of neurons and in the increased representation along the AP axis. Although the proportional difference in motoneuron number in the quail and chick roughly corresponds to the difference in the size of the limb muscles (see Tanaka and Landmesser, ' $86 \mathrm{~b}$ ), we have not detected an obvious increase in the relative size of the adductor muscles in quail that would conform to the proportionally higher numbers of neurons in this pool; however, we have not made a sufficiently detailed morphometric analysis to detect a small but significant difference.

An ongoing period of neuronal cell death during the stages we examined could theoretically account for a heterogeneity in motoneuron pool size and slight differences in A-P length of pools seen in both species. Whereas it has long been thought that cell death in chicken embryos is rare after stage 35, (see Hamburger, '75; Oppenheim, '81), Williams et al. ('87) have recently documented a late and regionally specific period of motoneuron cell death in chick; $55 \%$ of the motoneurons that die in the caudal segments do so between stage 35 and 38 . However, the quail pools in which we found the greatest deviations do not lie predominantly in the caudal segments. Although a late period of cell death may change the final number of motoneurons from that reported in both chick and quail, it is unlikely to radically alter pool positions, the parameter we are most concerned with in this work.

\section{Motoneuron projection pattern in the quail}

The gross anatomical nerve pattern in the quail hindlimb is remarkably similar to that in the chick (Fig. 8A-E). In both animals the spinal nerves meet at the base of the limb and form two plexuses. Neurites from LS segments 1-3 contribute to the crural (anterior) plexus. The dorsal nerve trunk from this plexus serves the sartorius, anterior iliotibialis, femorotibialis, and deep dorsal muscles as well as the anterior and posterior cutaneous nerves, whereas the ventral nerve trunk serves the obturators and adductors. As in the chick, none of the crural motor nerves penetrate the shank. The quail sciatic (posterior) plexus contains neurites originating in LS segments 3 through 7 and gives rise to a dorsal nerve trunk that serves the posterior iliotibialis, iliofibularis, and dorsal shank muscles and a ventral trunk that serves the ischioflexorius, caudilioflexorius, and ventral shank muscles. We found only very minor variations in the gross anatomical nerve pattern within individual limbs of quail such as additional branches in cutaneous (Fig. $8 \mathrm{C}, \mathrm{D})$ and muscle nerves.

We found differences in the segmental projection patterns that are a direct result of the compression of the chick map into seven segments and of the other shifts in $\mathrm{AP}$ position of pools described above. These differences have practical consequences, particularly since assessing the segmental projection pattern is the most straightforward way to determine the specificity of projection following surgical manipulations and has often been the assay of choice (e.g., Lance-Jones and Landmesser, '81b; Summerbell and Stirling, '81; Whitelaw and Hollyday, '83; Tosney and Landmesser, '84). For easy access to investigators, we present examples of projection patterns following injections 

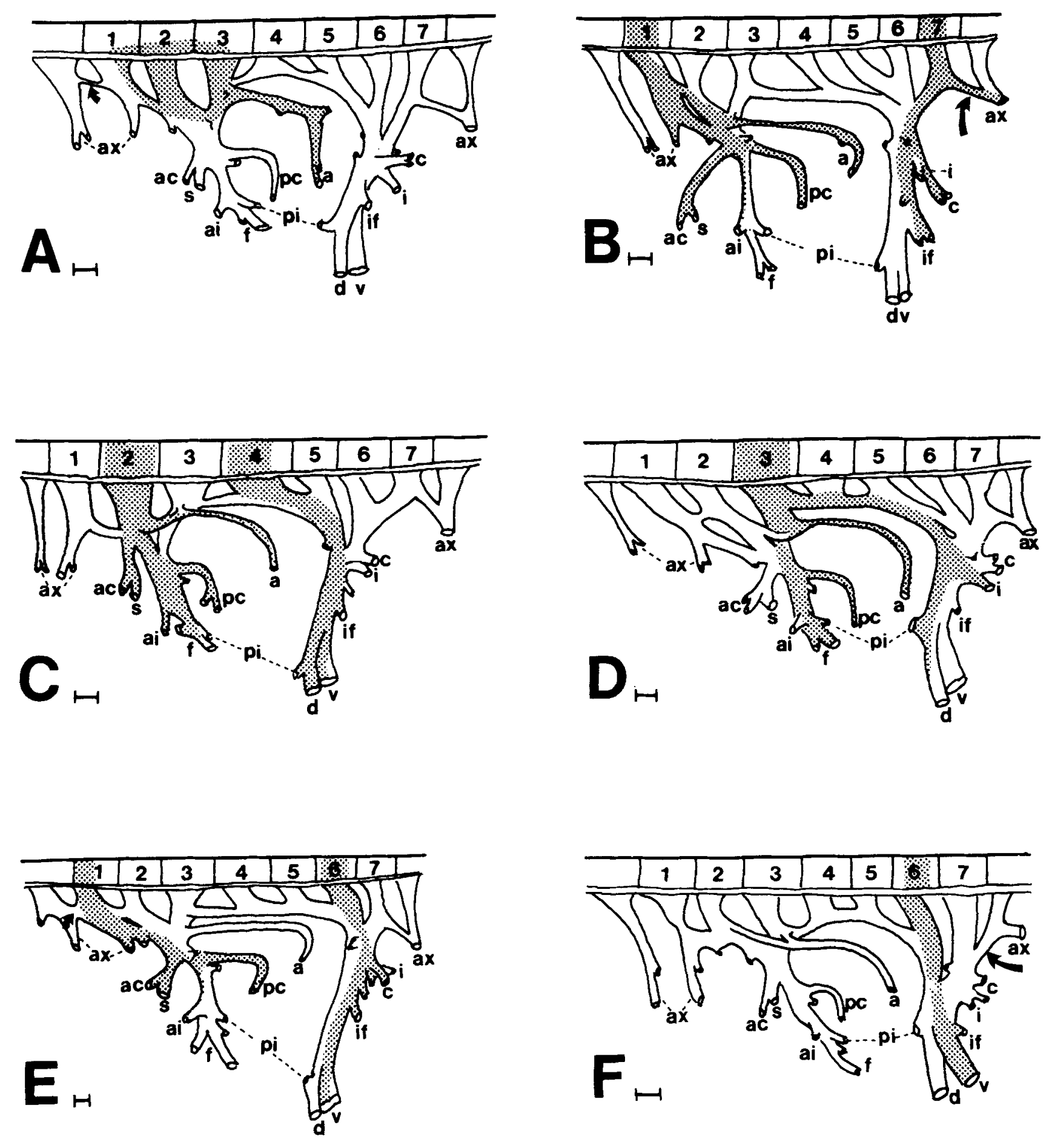

Figure 8 
into spinal nerves and discuss the more obvious differences and practical concerns in Figure 8A-F.

The differences between quail and chick projection patterns were, however, confined solely to differences in segmental projection pattern. Spinal nerves contained different complements of motor pools than in chick, in accord with the identity of motor pools in the corresponding quail spinal cord segment. However, once quail axons reached the plexus region, they sorted out in a manner indistinguishable from that previously described in chick (Lance-Jones and Landmesser, '81a; Tosney and Landmesser, '85b), Axons from particular motoneuron pools came to lie in stereotyped regions within the nerve trunks that presaged their position of exit into the appropriate muscle nerves (e.g., Fig. 8B,D,E). In addition, as previously described in chick (Tosney and Landmesser, '85c), quail growth cones

Fig. 8. Reconstructions of the patterns of segmental projection to the quail hindlimb. Anterior is to the left. LS segments of the spinal cord are indicated by numbers. Axons and somata labeled by injection of HRP into spinal nerves or nerve trunks are indicated by stippling. $\mathbf{A}$. HRP injection into the ventral crural nerve trunk labeled medial motoneurons in LS1-3, in accord with the position of the adductors pool. Note that labeled axons were mixed with unlabeled axons within the spinal nerve and sorted out in the crural plexus region to enter the ventral nerve trunk. A small contribution from the last thoracic segment (arrow) indicates a slight shift in motor column position toward the anterior. B. Axons labeled by HRP injection into the anterior portions of spinal nerves 1 and 7 project in accord with the identity of pools in the corresponding spinal cord segment. Since injections label only a proportion of the axons present, few axons may be labeled when only the anterior or posterior trailing edge of a pool is present in the segment, as is the case with the anterior iliotibialis pool Labeled axons in segment 7 sort out in the plexus region and take up posterior position in the sciatic nerve trunk, in accord with their more distal exit points into caudilioflexorius and iliofibularis muscle nerves. LS7 does not contribute significantly to ventral shank innervation as it does in chick but does contribute to innervation of axial muscles posterior to the limb (arrow), which it never does in chick. C. LS2 projects to a similar complement of muscles in quail and chick. As in chick, LS4 does not project to the crural plexus. Injection into LS4 is more likely to label axons to the iliofibularis than similar injections in chick due to the greater representation of this pool in quail segment 4 , and is much less likely to label axons to the ischioflexorius. D. The projection of LS3 is similar to chick, except for a contribution to the adductors, which is uncommon in chick. Axonal sorting out is particularly clear; one population crosses the sciatic plexus to project to the ischioflexorius, whereas another takes up an anterior position to project to the posterior iliotibialis and a subset of dorsal shank muscles. $\mathbf{E}$. As in B, injections into areas such as anterior LS1 that contain the trailing edge of pools may label few (anterior iliotibialis) or no (adductors) axons from those pools. The segmental projection from LS 6 differs from chick in contributing to the caudilioflexorius. The lumbosacral motor column appears to be slightly shifted toward the anterior in this embryo, as evidenced by a contribution from the last thoracic segment (arrow). A rostral shift would place only the trailing end of dorsal shank pools in LS6, as is consistent with the absence of label to the dorsal shank. F Example of a postfixed projection pattern in which the entire lateral motor column is shifted caudally by half a segment, as indicated by a significant contribution from the segment posterior to LS7 (arrow). Injection into LS6 confirms the shift in pool position; unlike similar injections in a somewhat prefixed pattern ( $\mathbf{E}$, left), LS6 makes no contribution to the caudilioflexorius. Abbreviations for muscle and cutaneous nerves: a, adductors; ac, anterior cutaneous; ai, anterior iliotibialis; ax, axial muscles; c, caudilioflexorius; d, dorsal shank; $f$ femorotibialis; i, ischioflexorius; if, iliofibularis; pc, posterior cutaneous; pi, posterior iliotibialis; s, sartorius; v, ventral shank. Segmentally disposed epaxial muscle nerves have been omitted and nerves to the deep dorsal muscles of the thigh have not been labeled. The reconstructions have not been corrected for variations in section angle. $\mathrm{F}$, stage 27 embryo; A, C, D, stage 28 embryos; B, stage 32 embryo; E, stage 33 embryo. Bars $=100 \mu \mathrm{m}$ examined at the points of pathway divergence in younger embryos tend to be larger, more complex, and traverse more complex trajectories than do growth cones in unbranched regions of the pathways (unpublished observations). It is to be emphasized that the projection pattern of pools within the quail $\lim b$ is identical in all respects to that seen in the chick. It is particularly intriguing that, despite the shift in quail pools in either direction along the AP axis of the spinal cord relative to chick, axons enter the same plexus region that their counterparts do in chick. These results support the proposition that similar axonal guidance cues are present in similar positions in the plexus and limbs of the two species. Moreover, our results reveal a previously unsuspected maintenace of pool position along the otherwise highly variable AP axis of the spinal cord that retains the pool position relative to the anterior and posterior plexus regions, further suggesting that maintenance of pool position relative to guidance cues in the plexus regions of the limb may be a primitive and conserved character during phylogeny.

\section{Individual variability along the AP axis}

We also found heterogeneity in the placement of pools in individual quail embryos; a pool could vary by \pm half a segment along the AP axis. For example, two peroneus longus pools (Fig. 9A,B) differ in their AP placement in two embryos; one (Fig. 9B) is displaced caudally by half a segment. These differences were not due to misassignment of segmental levels, to incomplete injections, or to injection of the incorrect muscles. We believe that these differences reflect a shift of the entire LS motor complex along the AP axis rather than the shift of individual pools relative to their neighbors. For instance, we found that a dorsal shank pool mapped on the other side of the spinal cord in the embryo illustrated in Figure 9B was also shifted caudally. We identified a total of four out of fifty-five embryos in which pools were shifted by half a segment; in all cases the shift was toward the posterior. In no case did we find a pool to be shifted on only one side of the embryo.

Although Sherrington in 1892 identified a shift in projection in a variety of species in which the entire segmental projection pattern to limbs varied by half a segment toward the anterior (prefixed pattern) or toward the posterior (postfixed pattern), this type of pattern variation has been largely de-emphasized in the current decade and has not been documented in the chick or quail. A close examination of the nerve pattern in the quail reveals pre- and postfixed patterns of projection. For instance, an extreme postfixed pattern (Fig. $8 \mathrm{~F}$ ) is characterized by a contribution from the segment posterior to LS7. A caudal shift in pools in the postfixed pattern is wholly consistent with the specific segmental projection patterns assessed by injections of HRP (compare Fig. 8E,F). A prefixed pattern is similarly characterized by a contribution to the limb from the last thoracic spinal nerve (arrows in Fig. 8A,E). From examination of the gross anatomical nerve patterns in 126 dissected quail embryos, we estimate that fewer than $10 \%$ of the individuals display an extreme shift in segmental projection pattern. Our reconstructed maps of pools represent the more common positions. We emphasize that, despite these variations in projection pattern in the environment proximal to the limb and regardless of the exact position of the motor column along the AP axis, the specific projection pattern is identical in all individuals because axons of 


\section{A. peroneus longus}

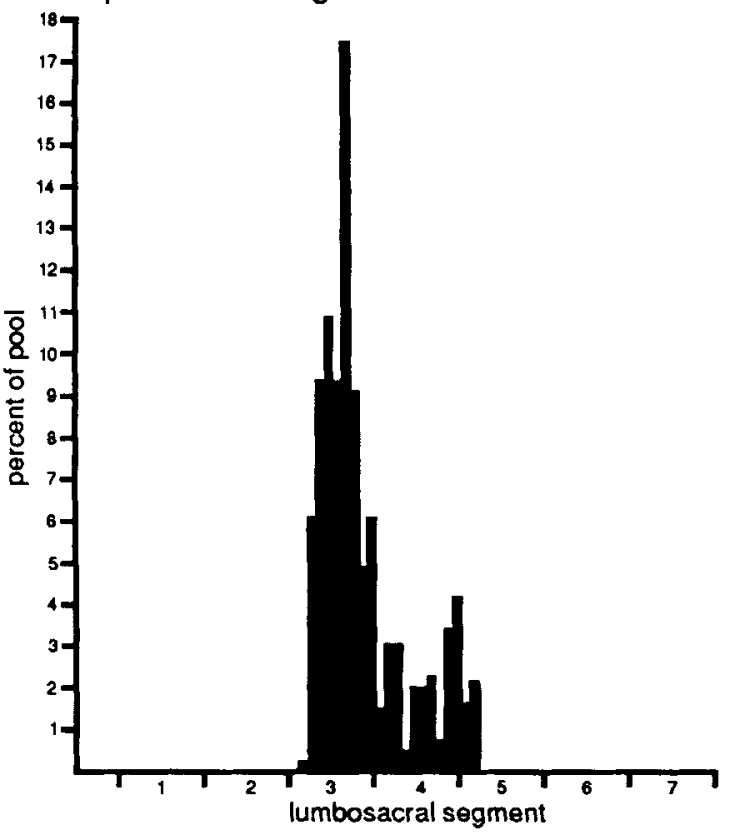

B. peroneus longus

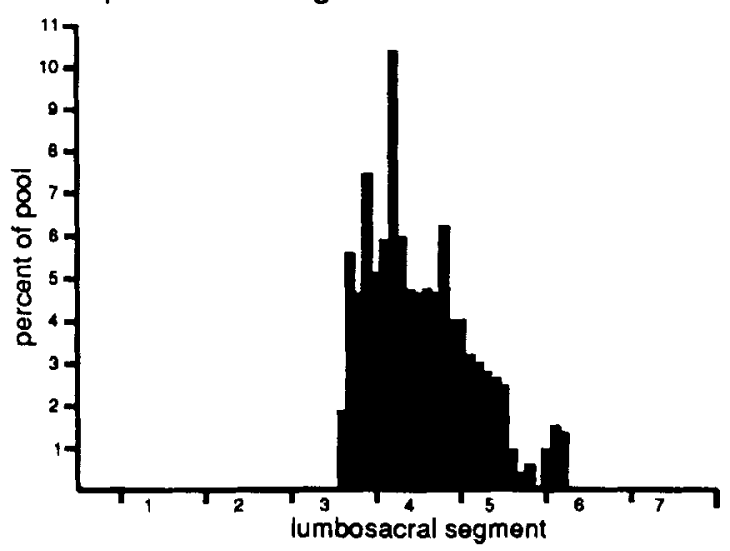

Fig. 9. Heterogeneity in the position of the lateral motor column along the AP axis. Data presented as in Figure 2. Two peroneus longus pools differ in their AP position in two embryos. The more common position, confirmed in 3 additional embryos, is shown in $\mathbf{A}$. The pool shown in $\mathbf{B}$ is shifted caudally by half a segment. A dorsal shank pool on the other side of this embryo was similarly shifted toward the posterior. Figure $8 \mathrm{~F}$ shows the reconstruction of an embryo with a similarly postfixed projection pattern.

individual pools sort out in an identical manner once they reach the base of the limb.

\section{DISCUSSION Medial-lateral position of pools}

The position of motoneuron pools within the transverse plane is remarkably consistent between the quail and chick. Although the relative ML relationship is known to be highly conserved in birds and mammals in general (see McHanwell and Biscoe, '81; Bennett, '83), there is seldom a clear ML relationship in the lateral motor columns of amphibians
(Cruce, '74; Stephens and Horder, '85; Wake et al., '88). In contrast, the medial motor column that innervates the axial muscles is clearly distinct from the lateral motor column that innervates extremities in four vertebrate classes (birds, mammals, reptiles and, with exceptions [Wake et al., '88], amphibians; see Nieuwenhuys, '64; Fetcho, '88). The degree of separation of medial and lateral motor columns and its ML subdivisions varies widely among fish (Droge and Leonard, '83; Fetcho, '86a; see also Nieuwenhuys, '64). For instance, the zebrafish has recently gained popularity as a model system precisely because individual neurons are often uniquely identifiable by position early in development (see Eisen et al., '86), yet motoneurons that innervate the two pectoral fin muscles completely overlap in mediallateral position with one another and with neurons that innervate the myotomal muscles (John Kuwada, personal communication). In contrast, even the ML subdivisions of the lateral motor column and an AP somatotopy is apparent in the stingray (Droge and Leonard, '83). Thus there appear to be variations in the elaboration of pools into separate anatomical entities across vertebrate classes, with the greatest delineation apparent in mammals (see Romanes, '64; Nieuwenhuys, '64; Fritz et al., ' $86 a, b$ ).

Until relatively recently, the phylogenetic conservation of relative pool position was considered to reflect the muscle's function as a flexor or extensor or the relative position of muscles within the adult (c.f., Sherrington, 1892; Goering, '28; Romanes, '51, '64; Szekely and Czeh, '67) where the conservation could reflect constraints upon central connectivity (see recent discussions by Fritz et al., '86; Wake et al., '88). However, pools to homologous muscles retain their relative position despite alterations in the function of muscles during evolution (see Cruce, '74; Landmesser, '78b; Bennett, '83; Fetcho, '88). Hughes ('68) was the first to suggest a key role for ontological relationships. Landmesser ('78b) provided cogent evidence that the ML position of pools in the chick is related to the developmental position of the corresponding muscles rather than to the function or position of the adult muscles. As we have also shown in the quail, pools located in medial positions consistently innervate muscles derived from the embryonic ventral muscle mass, whereas lateral pools innervate muscles derived from the dorsal muscle mass.

This correspondence was originally suggested to be important to axonal target selection (Landmesser, '78; Hollyday, ' 80 ), but the more important correlation is likely to be between pool position and the selection of pathways within the limb. The medial motoneurons invariably project into ventral nerve trunk pathways, whereas lateral motoneurons invariably project into dorsal nerve trunk pathways (see Landmesser, '87). This DV projection pattern reflects the first decision axons make between alternative pathways as they enter a limb. Once axons have made this choice, they are generally unable to compensate for experimental alterations in the DV position of tissues within the limb (Summerbell and Stirling, '81; Ferguson, '83; Whitelaw and Hollyday, '83; Lance-Jones, '86). The irrevocable nature of this pathway decision contrasts markedly with the plasticity shown of axonal projection along the AP axis within plexuses or within the limb (Lance--Jones and Landmesser, ' $80 \mathrm{~b}$, ' $81 \mathrm{~b}$ ). The DV pathway choice is thus in some real sense a primary pathway choice and it is most intriguing that it corresponds with the most highly conserved parameter of motor pool organization. 
The correspondence also suggests that the specification of pools along the ML axis and the specification of axonal guidance cues along the DV axis are conservatively coordinated throughout several vertebrate classes during development. The essential navigation cues for the DV pathway choice may be largely confined to the plexus region, since axons make this choice correctly even in the absence of the target muscles or of the entire limb (Tosney and Landmesser, '84). Both plexus tissue and limb motoneurons can be supposed to display chemical recognition molecules that correspond to and mediate the DV pathfinding choice. In addition, neurites may interact in accord with their $\mathrm{ML}$ identity, specifically fasciculating with like neurites and avoiding unlike neurites. Several workers have recently documented interactions of this sort among other neural populations (Raper et al., '83; Kapfhaemmer and Raper, '87). The ML pool position may be so highly conserved because it correlates with an equally conserved and primary axonal pathfinding choice in the limb and because normal development demands coordinate specification of the pools and the guidance cues.

\section{Anterior-posterior position of pools}

The most highly maintained parameter of pool position along the A-P axis is at the level of groups of pools. Our most unexpected observation was the finding that the positions of pools relative to their projection into anterior or posterior plexus regions and the corresponding nerve trunks in the quail and chick limb were preserved, and that the pools in quail were not merely compressed from the posterior toward the anterior relative to the chick. Because the map in quail is compressed about a central point, segment three, the relative positions of anterior pools and the crural plexus and of posterior pools and the sciatic plexus is the same in both species. The preservation of this spatial relationship is likely to reflect the restriction of appropriate axonal guidance cues to crural versus sciatic plexus regions. Whereas axons may normally originate from slightly different AP positions in chick and quail (or in individuals within each species), there is evidence that they depend primarily upon guidance cues within the plexus and limb to innervate appropriately. Axons are able to compensate for slight experimental displacements along the AP axis that retains their access to the appropriate plexus region, but are less able to make pathway corrections when they are channeled into an inappropriate plexus region (LanceJones and Landmesser, ' $80 \mathrm{~b}$, '81b). Our study also demonstrates that quail axons sort out into like populations when in the plexus regions despite their entry from several spinal nerves, despite their being spatially mixed with other populations while within the spinal nerves, and despite a sliding of the AP position of the entire motor column. A similar individual variability in projection to the plexus region and constancy of projection within the limb is characteristic of several vertebrate orders (Sherrington, 1892; Romanes, '51, '64; Cruce, '74). It is as though axons may approach the limb in any manner and as long as they enter the plexus that they usually would, they innervate precisely. These considerations suggest that the conservation of pool positions in relation to the plexus regions is a function of the confinement of essential guidance cues to each plexus region. Moreover, and of great interest to phylogenetic processes, these observations suggest that the access of axons to the appropriate plexus region exerts a major selection pressure on the position of pools along the $\mathrm{AP}$ axis.

In other respects, the pool positions along the AP axis show the most variation between the chick and quail of all positional parameters, despite the rough correspondence of pool and muscle position along the AP axis in both species. We document a number of differences, most of which can be attributed to a compression of an eight segment map into seven segments, and some of which reflect true interspecies divergence. In addition, the position of the lateral motor column varies along the AP axis in individuals. The regions of highest cell density within pools were also in several cases in different positions along the $\mathrm{AP}$ axis than in chick. Shifts in cell density can also be produced experimentally within chick pools. For example, the posterior portion of the pool contains more motoneurons than is usual after the cell death period when an anterior portion of a pool is deleted (Lance-Jones and Landmesser, ' $80 \mathrm{a}$ ) or when more mature quail somites are transplanted adjacent to a pool (LanceJones, '88a). These workers ascribe such differences to spatial differences in motoneuron death that result from some bias in interactions of motoneurons with one another or with the target along the AP axis. Regional variations may also arise from differential proliferation patterns (Tanaka and Landmesser, ' $86 \mathrm{~b}$; Oppenheim et al., ' 89 ). The spatial distribution of neurons within a pool is thus at least partially a product of complex interactions after the initial specification of motoneuron identity, and it is not surprising to find that this aspect of pool shape may vary among species.

As a result of the AP differences in pool position, the segmental pattern of projection in quail is different from that in chick (see also Tanaka and Landmesser, '86a). However, whereas segments may project to different muscle nerves in the quail than in the chick, in both species the identity of the motoneurons within any particular nerve in the limb is the same. Motoneurons projecting out different subsets of spinal nerves sort out in the plexus region in identical fashion, so that the specific pattern of pool projection is identical within the limb of both species.

The variation along the $\mathrm{AP}$ axis extends to a variation in the pattern among individuals of a species. There is a strong precedence for the idea that the LS motor column may slide along the AP axis in individuals of a species. Sherrington in 1892 identified a shift in projection in a variety of species in which the entire segmental projection pattern to limbs, as assessed by the gross anatomy and by physiological stimulation, varied by \pm half a segment along the $\mathrm{AP}$ axis. He defined two extreme patterns, a prefixed pattern with a rostral shift and a postfixed pattern with a caudal shift. This observation has since been confirmed in the LS columns of cat (Romanes, '51, '64) and frog (Cruce, '74) and is consistent with some variations noted by Hollyday ('80) in chick. Whereas this type of pattern variation has been largely ignored in this decade, it is widely known among practitioners in this field that the projection pattern may be in an extreme prefixed arrangement in as many as $5 \%$ of the chick embryos examined, and such embryos are often discarded (Scott, '82; Cynthia Lance-Jones, Lynn Landmesser, personal communications; Tosney, unpublished observations). Since individuals of a species vary in this way, caution is advisable in experiments that seek to detect errors in projection. Differences in the usual pattern of projection from motoneurons at the trailing anterior and posterior ends of a pool do not necessarily indicate errors in 
projection, either during normal or experimentally perturbed development. Errors in projection can be distinguished from natural differences in the AP position and extent of a pool only when the central portion of a pool is examined.

The variable segmental position of the entire complex of LS pools in a number of species (c.f., Sherrington, 1892; Romanes, '51; Cruce, '74) strongly suggests that specification of motoneuron identity along the AP axis is not related in any causal manner to the segmental patterning of the somites. Indeed, it was apparent very early on that the AP positions of motor groups are not altered to correspond with natural variations in the number of the somitically derived vertebral segments (Sherrington, 1892). It is now clear that the segmental origin of limb muscles also provides no specific axonal guidance cues, further suggesting that somites, limb targets, and motoneurons are not specified by corresponding segmental positions (Lance-Jones, '88a). Instead, the AP length of the motor column appears to correspond to the relative extent of the limb bud along this same axis. As hypothesized by Tanaka and Landmesser ('86a), this relationship suggests that the position-dependent identity of both motoneurons and the limb may be specified by the same or a spatially related embryonic field. The somatopleure at the limb base gives rise to the plexus mesenchyme, which is so important to axonal guidance; it also forms the connective tissue of the limb, which is thought to specify the identity of limb muscles (see LanceJones, ' $88 \mathrm{~b}$ ). Motoneurons and somatopleure may gain coordinate identities that are vital to subsequent axonal guidance and neuron-target matching. If this were so, it would provide a teleologically satisfying explanation for the spatial concordance in AP extent between the lateral motor columns and the extremities that they innervate in different species.

The anatomical segmentation of axons into spinal nerves is imposed by the somite (Detwiler, '34). Since the segmental projection of pools varies in individual embryos, the process of axonal segmentation is clearly independent of the AP disposition of pools; there is no mechanism to assure that a particular motor pool always exits the cord through a stereotyped subset of spinal nerves. In addition, there is experimental evidence that the process of axonal segmentation is irrelevant to the specific projection pattern within the limb. Even when axons grow out in a completely unsegmented pattern after deletion of all LS somites, motor axons project to the appropriate limb muscles with their normal high precision (Tosney, '88b). Axonal segmentation is thus a secondary response to the embryonic anatomy outside the spinal cord (see review by Tosney, '88a). Since axonal segmentation can be dissociated from the development of specific neuromuscular connections, there are no strong selection pressures to assure that the motoneuron pools are ordered in accord with segmental structures.

We conclude that specific guidance cues for motoneurons that innervate extremities are independent of whatever segment-specific characteristics develop within somites. In our view, the somitic environment molds only the gross anatomy of axonal projection and assures that spinal nerves are appropriately positioned in accord with the vertebral tissues that come to surround them (see also Tosney, ' $88 \mathrm{a}, \mathrm{b}$ ). Unlike motoneurons of the medial motor column that innervate segmentally arrayed targets (see Fetcho, '88 for review), motoneurons of the lateral motor column appear to have won independence from a segmental mode of specification or organization and from any constraints on specific axonal pathfinding that could be imposed by the development of segmental structures.

\section{The use of quail-chick chimeras to study axon guidance}

We have described parameters that must be taken into account in designing and interpreting experiments on neuromuscular development in the hindlimb using the quail chick chimera technique. The most obvious differences are in the segmental position of motor pools. We also emphasize individual variation in the AP position of the LS motor column and suggest how the rarer prefixed and postfixed anatomical situations may be detected before detailed analysis simply by observing the gross anatomy of the proximal nerve pattern. In addition, since the maximal pool shift is on the order of a segment and since most pools cover two-four segments, any particular pool should be identifiable by concentrating on the central segments containing the pool in both normal and chimeric spinal cords. The two species are also known to differ in developmental rate and in ultimate size: the small quail embryo develops more quickly, hatching in 18 rather than 21 days, size differences in the limb become apparent by stage 30 at about 6 days of incubation, and limbs retain their speciesspecific rate of development when transplanted in chimeric surgeries (Tanaka and Landmesser, ' $86 \mathrm{~b}$; see also LanceJones, ' $88 \mathrm{a}, \mathrm{b})$. These realities place spatial and temporal constraints on the types of interspecific transplants that will be practicable.

Our study also helps to validate the utility of the chimera approach in this system by identifying many similarities between the species, the most striking of which are the preservation of pool positions within the transverse plane and the constant patterns of specific projections within the limb. In addition, the limb muscles do not significantly differ in size or morphology at the early stages when innervation is developing (Grim et al., '83; Tanaka and Landmesser, '86b; Schroeter and Tosney, '89 and unpublished observations). Studies that have used quail chick chimeras to examine axon guidance suggest that quail and chick growth cones do navigate with precision in chimeric animals (Heaton, '73; Alvarado-Mallart and Sotelo, '84); in particular, motoneurons make functional and appropriate connections with limb muscles of the complementary species in chimeras (Tanaka and Landmesser, '86a). The availability of an antiserum that specifically recognizes quail cells greatly increases the promise of the chimeric technique for studies of axon guidance, since axons as well as cell bodies may be distinguished when quail motoneurons are transplanted into a chick environment (LanceJones and Lagenaur, '87). When due respect and allowance for the differences is made, it is likely that studies using chimeras will help researchers reveal the location and nature of axonal guidance cues.

\section{ACKNOWLEDGMENTS}

We thank Robert Oakley for criticizing the manuscript, Denise Dehnbostle for aid in figure preparation, and Mary McKitrick for aid in determining muscle nomenclature. This work was supported by NIH grant \# NS-21308 to K.T. A portion of this work comprised the undergraduate honors 
thesis of S.T. S.S. was partially supported by NIH training grant \# HD-07274.

\section{LITERATURE CITED}

Alvardo-Mallart, R-M., and C. Sotelo (1984) Homotopic and heterotopic transplantations of quail tectal primordia in chick embryos: Organization of the retinotectal projections in the chimeric embryos. Dev. Biol. 103:378-398

Bennett, M.R. (1983) Development of neuromuscular synapses. Physiol. Rev. 63:335-357

Cruce, W.L.R. (1974) The anatomical organization of hindlimb motoneurons in the spinal cord of the frog, R. catesbiana. J. Comp. Neurol. 153:59-76.

Detwiler, S.R. (1934) An experimental study of spinal nerve segmentation in Amblystoma with reference to the plurisegmental contribution to the brachial plexus. J. Exp. Zool. 67:395-441.

Droge, M.H., and R.B. Leonard (1983) Organization of spinal motor nuclei in the stingray, Dasyatis sabina. Brain Res. 276:201-211.

Eisen, J.S., P. Meyers, and M. Westerfield (1986) Pathway selection by growth cones of identified motoneurons in live zebrafish embryos. Nature (London) 320:269-271.

Ferguson, B. (1983) Development of motor innervation of the chick following dorsal-ventral limb bud rotations. J. Neurosci. 3:1760-1772.

Fetcho, J.R. (1986a) The organization of the motoneurons innervating the axial musculature of vertebrates. I. Goldfish (Carassius auratus) and mudpuppies (Necturus maculosus). J. Comp. Neurol. 249:521-550.

Fetcho, J.R. (1986b) The organization of the motoneurons innervating the axial musculature of vertebrates. II. Florida water snakes (Nerodia fasciata pictiventris). J. Comp. Neurol. 249:551-563.

Fetcho, J.R. (1988) A review of the organization and evolution of motoneurons innervating the axial musculature of vertebrates. Brain Res. Revs. $12: 243-280$

Fritz, N., M. Illert, and P. Saggau (1986a) Location of motoneurones projecting to the cat distal forelimb. I. Deep radial motor nuclei. J. Comp. Neurol. 244:286-301.

Fritz, N., M. Illert, and P. Saggau (1986b) Location of motoneurones projecting to the cat distal forelimb. II. Median and Ulnar motor nuclei. J. Comp. Neurol. 244:302-312

Goering, J. (1928) An experimental analysis of the moto-cell columns in the cervical enlargement of the spinal cord in the albino rat. J. Comp. Neurol, 46:125-151.

Grim, M., B. Christ, I. Klepacek, and M. Vrabcova (1983) A comparison of motor end plate distribution and the morphology of some wing muscles of the chick and quail. Histochem. J. 15:289-291.

Hamburger, V. (1975) Cell death in the development of the lateral motor column of the chick embryo. J. Comp. Neurol. 160:535-546.

Hamburger, V., and H. Hamilton (1951) A series of normal stages in the development of the chick embryo. J. Comp. Neurol. 160:535-545.

Heaton, M. (1973) Xenoplastic eye transplantation between chick and quail embryos: Some neuroanatomical and functional aspects. J. Comp. Neurol. 151:359-376.

Hollyday, M. (1980) Organization of motor pools in the chick lumbar lateral motor column. J. Comp. Neurol. 194:143-170.

Hughes, A. (1968) Aspects of Neural Ontology. London: Logos Press.

Kapfhaemmer, J.P., and J.A. Raper (1987) Interactions between growth cones and neurites growing from different neural tissues in culture. J. Neurosci. 7:1595-1600.

Lance-Jones, C.C. (1986) Motoneuron projection patterns in chick embryonic limbs with a double complement of dorsal thigh musculature. Dev. Biol. 116:387-406.

Lance-Jones, C. (1988a) The effect of somite manipulation on the development of motoneuron projection patterns in the embryonic chick hindlimb. Dev. Biol. 126:408-419.

Lance-Jones, C. (1988b) The somitic level of origin of embryonic hindlimb muscles. Dev. Biol. 126:394-407.

Lance-Jones, C.C., and C.F. Lagenaur (1987) A new marker for identifying quail cells in embryonic avian chimeras: A quail-specific antiserum. J. Histochem. Cytochem. 35:771-780.

Lance-Jones, C., and L. Landmesser (1980a) Motoneuron projection pat- terns in the chick hindlimb following early spinal cord deletions. J. Physiol. Lond. 302:559-580.

Lance-Jones, C., and L. Landmesser (1980b) Motoneuron projection patterns in the chick hindlimb following early partial spinal cord reversals. J. Physiol. Lond. 302:581-602.

Lance-Jones, C., and L. Landmesser (1981a) Pathway selection by chick lumbosacral motoneurons during normal development. Proc. R. Soc. Lond (B) 214:1-18.

Lance-Jones, C., and L. Landmesser (1981b) Pathway selection by embryonic chick motoneurons in an experimentally altered environment. Proc R. Soc. Lond. (B) 214:19-52

Landmesser, L. (1978a) The distribution of motoneurons supplying chick hindlimb muscles. J. Physiol. 284:371-389.

Landmesser, L. (1978b) The development of motor projection patterns in the chick hindlimb. J. Physiol. 284:391-414.

Landmesser, L. (1987) Peripheral guidance cues and the formation of specific motor projections in the chick. In S.S. Easter, K.F. Baraid, and B.M. Carlson (eds): From Message to Mind: Directions in Developmental Neurobiology. Sunderland, MA: Sinauer, pp. 121-133.

Le Douarin, N. (1973) A biological cell labeling technique and its use in experimental embryology. Dev. Biol. 30:217-222.

McHanwell, S., and T.J. Biscoe (1981) The localization of motoneurons supplying the hindlimb of the mouse. Proc. Roy. Soc. B. 293:477-508.

Nieuwenhuys, R. (1964) Comparative anatomy of the spinal cord. In J.C Eccles and J.P. Schade (eds): Progress in Brain Research, Organization of the Spinal Cord. Vol. 11. Amsterdam: Elsevier/North Holland Biomedical Press, pp. 1-57.

Oppenheim, R.W. (1981) Neuronal cell death and some related regressive phenomena during neurogenesis: A selective historical review and progress report. In W.M. Cowan (ed): Studies in Developmental Neurobiology: Essays in Honor of Viktor Hamburger. New York: Oxford University Press, pp. 74-133.

Oppenheim, R.W., T. Cole, and D. Prevette (1989) Early regional variations in motoneuron numbers arise by differential proliferation in the chick embryo spinal cord. Dev. Biol. 133:468-474.

Raper, J.A., M. Bastiani, and C.S. Goodman (1983) Pathfinding by neuronal growth cones in grasshopper embryos. II. Selective fasciculation onto specific axonal pathways. J. Neurosci. 3:31-41.

Romanes, G. (1951) The motor cell columns of the lumbosacral spinal cord of the cat. J. Comp. Neurol. 94:313-363.

Romanes, G. (1964) The motor pools of the spinal cord. Prog. Brain Res. 11:93-119

Romer, A. (1927) The development of the thigh musculature of the chick. J. Morphol, 43:347-385.

Schroeter, S., and K.W. Tosney (1989) Timing and direction of muscle cleavage in the chick thigh. Soc. Neurosci. Abs. 14:581.

Scott, S.A. (1982) The development of the segmental pattern of skin sensory innervation in embryonic chick hind limb. J. Physiol. 330:203-220.

Sherrington (1892) Note on the arrangement of some motor fibres in the lumbar-sacral plexus. J. Physiol. Lond. 13:621-772.

Silver, M. (1942) The motoneurons of the spinal cord of the frog. J. Comp. Neurol. 82:1-26.

Stephens, N., and N. Holder (1985) A horseradish peroxidase study of motoneurons pools of the forelimb and hindlimb musculature of the axolotl. Proc. R. Soc. Land. B. 224:325-339.

Streeter, G.L. (1904) The structure of the spinal cord of the ostrich. Am. J. Anat. 3:1-27.

Summerbell, D., and R. Stirling (1981) The innervation of dorsoventrally reversed chick wings: Evidence that motor axons do not actively seek out their appropriate targets. J. Embryol. Exp. Morph. 61:233-247.

Szekely, G., and G. Czeh (1967) Localization of motoneurones in the limb moving spinal segments of Ambystoma. Acta Physiol. Hung. 32:3-18.

Tanaka, H., and L.T. Landmesser (1986a) Interspecies selective motoneuron projection patterns in chick-quail chimeras. J. Neurosci. 6:2880-2888.

Tanaka, H., and L.T. Landmesser (1986b) Cell death of lumbosacral motoneurons in chick, quail, and chick-quail chimera embryos: A test of the quantitative matching hypothesis of neuronal cell death. J. Neurosci. 6:2889-2899.

Tosney, K.W. (1988a) Somites and axon guidance. Scanning Microsc. 2 (88):427-442.

Tosney, K.W. (1988b) Proximal tissues and patterned neurite outgrowth at 
the lumbosacral level of the chick embryo: Partial and complete deletion of the somite. Dev. Biol. 127:266 286.

Tosney, K.W., and L.T. Landmesser (1984) Pattern and specificity of axonal outgrowth following varying degrees of chick limb bud ablation. I. Neurosci. 4:2518-2527.

Tosney, K.W., and L.T. Landmesser (1985a) Development of the major pathways for neurite outgrowth in the chick hindlimb. Dev. Biol. 109:193-214.

Tosney, K.W., and L.T. Landmesser (1985b) Specificity of motoneuron growth cone outgrowth in the chick hindlimb. J. Neurosci. 5:2336-2344.

Tosney, K.W., and L.T. Landmesser (1985c) Growth cone morphology and trajectory in the lumbosacral region of the chick embryo. J. Neurosci. 9:2345-2358

Vanden Berge, J.C. (1979) Myologia. In J.J. Baumel, A.S. King, A.M. Lucas,
J.E. Breazile, and H.E. Evans (eds): Nomina Anatomica Avium. London: Academic Press, pp. 175-219.

Wake, D.B., K.C. Nishikawa, U. Dicke, and G. Roth (1988) Organization of the motor muclei in the cervical spinal cord of salamanders. J. Comp. Neurol. 278:195-208.

Whitelaw, V., and M. Hoilyday (1983) Neural pathway constraints in the motor innervation of the chick hindlimb following dorsoventral rotations of distal leg segments. J. Neurosci. 3:1226-1233.

Williams, C., G. Wohlenberg, and M.J. O'Donovan (1987) Regional variations in the extent and timing of motoneuron cell death in the lumbosacral spinal cord of the chick embryo. Dev. Brain Res. 34:215-221.

Wortham, R.A. (1948) The development of the muscles and tendons in the lower leg and foot of chick embryo. J. Morph. 83:105-148. 